\title{
Neutron Monitoring of Plutonium at the ZPPR Storage Vault
}




\section{DISCLAIMER}

This report was prepared as an account of work sponsored by an agency of the United States Government. Neither the United States Government nor any agency Thereof, nor any of their employees, makes any warranty, express or implied, or assumes any legal liability or responsibility for the accuracy, completeness, or usefulness of any information, apparatus, product, or process disclosed, or represents that its use would not infringe privately owned rights. Reference herein to any specific commercial product, process, or service by trade name, trademark, manufacturer, or otherwise does not necessarily constitute or imply its endorsement, recommendation, or favoring by the United States Government or any agency thereof. The views and opinions of authors expressed herein do not necessarily state or reflect those of the United States Government or any agency thereof. 


\section{DISCLAIMER}

Portions of this document may be illegible in electronic image products. Images are produced from the best available original document. 
This work was supported by the US Department of Energy, Office of Safeguards and Security.

Edited by Dorothy C. Amsden, Q-2

Composition and layout by Belinda K. Haag, Q-2

Illustrations by A. Gayle Smith, Q-2

\section{DISCLAIMER}

This report was prepared as an account of work sponsored by an agency of the United States Government. Neither the United States Government nor any agency thereof, nor any of their employees, makes any warranty, express or implied, or assumes any legal liability or responsibility for the accuracy, completeness, or usefulness of any information, apparatus, product, or process disclosed, or represents that its use would not infringe privately owned rights. References herein to any specific commercial product, process, or service by trade name, trademark, manufacturer, or otherwise, does not necessarily constitute or imply its endorsement, recommendation, or favoring by the United States Government or any agency thereof. The views and opinions of authors expressed herein do not necessarily state or reflect those of the United States Government or any agency thereof. 


\title{
Neutron Monitoring of Plutonium at the ZPPR Storage Vault
}

\author{
J. T. Caldwell \\ T. H. Kuckertz \\ J. M. Bieri \\ S. W. France \\ R. W. Goin* \\ R. D. Hastings \\ J. C. Pratt \\ E. F. Shunk
}

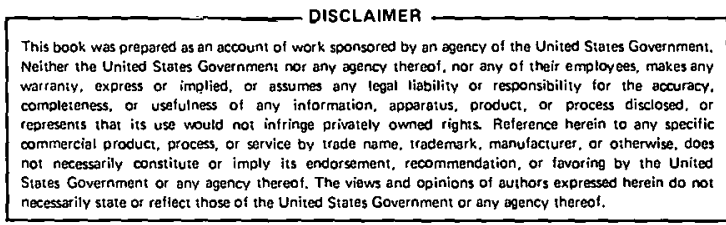

*Idaho National Engirieering Laboratory, Idaho Falls, ID 83401.
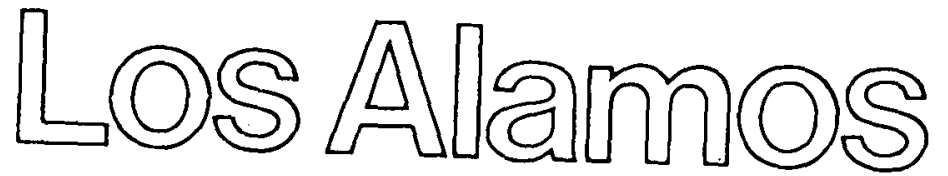

Los Alamos National Laboratory Los Alamos, New Mexico 87545 


\section{PAGES ii to iii WERE INTENTIONALLY LEFT BLANK}




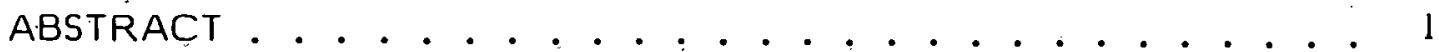

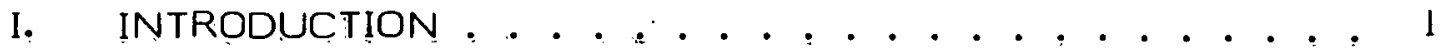

II. DEVELOPMENT OF THE VAULTT MONITORING SYSTEM. . . . . . 2

III. STATISTICS USED FOR DATA ANALYSIS . . . . . . . 8

IV. DATA ACQUISITION EQUIPMENT AND SOFTWARE. . . . . 10

V. IMPROVEMENTS TO SYSTEM PERFORMANCE. ...... 13

VI, PLUTONIUM REMOVAL EXPERIMENTS . . . . . . . . 17

VIII. CONCLUSIONS AND SUMMARY . . . . . . . . . . 24

ACKNOWLEDGMENTS . . . . . . . . . . . 26

REFERENCES. . . . . . . . . . . . 26

GLOSSARY . . . . . . . . . . . . . 28 
NEUTRON MONITORING OF PLUTONIUM AT THE ZPPR STORAGE VAULT

by

J. T. Caldwell, T. H. Kuckertz,

J. M. Bieri, S. W. France, R. W. Goin,

R. D. Hastings, J. C. Pratt, and E. R. Shunk

\begin{abstract}
We investigated a method for monitoring a typical large storage vault for unauthorized removal of plutonium. The method is based on the assumption that the neutron field in a vault produced by a particular geometric configuration of bulk plutonium remains constant in time and space as long as the configuration is undisturbed. To observe such a neutron field, we installed an array of 25 neutron detectors in the ceiling of a plutonium storage vault at Argonne National Laboratory West. Each neutron detector provided an independent spatial measurement of the vault neutron field. Data collected by each detector were processed to determine whether statistically significant changes had occurred in the neutron field. Continuous observation experiments measured the long-term stability of the system. Removal experiments were performed in which known quantities of plutonium were removed from the vault. Both types of experiments demonstrated that the neutron monitoring system can detect removal or addition of bulk plutonium $\left(11 \%{ }^{240} \mathrm{Pu}\right)$ whose mass is as small as $0.04 \%$ of the total inventory.
\end{abstract}

\title{
I. INTRODUCTION
}

Research facilities that maintain large inventories of plutonium need a method for monitoring their storage vaults to detect unauthorized removal of plutonium in a timely fashion. This report describes the vault monitoring system, designed and constructed at Los Alamos National Laboratory and tested at Argonne National Laboratory West, that provides a reliable and inexpensive method for monitoring large storage vaults.

The vault monitoring system provides continuous surveillance by measuring changes in a vault's neutron field. These changes reflect whether pluturium has been added to or removed from the vault, pinpoint the location, and indicate how much plutonium is involved. 
Bulk plutonium in storage vaults generally is a mixture of several isotopes. The principal source of neutrons emitted by typical metallic plutonium is ${ }^{240} \mathrm{Pu}$, which fissions spontaneously at a rate of approximately $1000 \mathrm{n} / \mathrm{s} / \mathrm{g}$. Thus, in a plutonium storage vault the strength of the neutron field at any place primarily depends on the mass and spatial distribution of ${ }^{240} \mathrm{Pu}$. Addition or removal of plutonium causes changes to the neutron field that can be measured using a geometrically appropriate array of neutron detectors.

To verify the effect of plutonium removal on a neutron field, the Los Alamos Detection and Verification Group installed a vault monitoring system in the Zero Power Plutonium Reactor (ZPPR) storage vault of Argonne West at the Idaho National Engineering Laboratory (INEL). The system consisted of an array of 25 neutron detectors and a data acquișition system. The detectors monitored the neutron field in the vault before and after known quantities of plutonium were relocated. The data collected by each detector were processed in an affiliated data acquisition system, which helped us determine whether statistically significant changes had occurred in the neutron field.

Using the vault monitoring system, we performed two types of experiments at ZPPR over an 8-month period to determine the system characteristics for measuring neutron fields associated with the plutonium in storage. In one type of experiment, known quantities of plutonium were removed from the vault, causing observable changes in the neutron field. In the second type of experiment, the vault neutron field was monitored continuously over extended periods ( 3 days to 2 weeks) when no activity occurred in the vault. The first type of experiment established the minimum quantity of plutonium whose removal the system could detect; the second type demonstrated the effects of long-term parameter drifts in the system components.

The results of these experiments show that the monitoring system can detect the removal from or addition to an inventory of $2500 \mathrm{~kg}$ of $1 \mathrm{~kg}$ of plutonium $\left(11 \%{ }^{240} \mathrm{Pu}\right)$ from any location in the vault with reasonable statistical certainty. Consistent results require long-term stability in the detectors and their high-voltage power supplies.

\section{DEVELOPMENT OF THE VAULT MONITORING SYSTEM}

In June 1978, the Detection and Verification Group contributed two technical proposals to a conceptual study entitled "Concepts for Inventory Verification in Critical Facilities." 1 The first proposal dealt with rapid verification of reactor fuel. drawers; ${ }^{2,3}$ the second dealt with monitoring plutonium on-line in a storage vault. ${ }^{4,5}$ Both proposals were subsequently funded by the Department of Energy (DOE) Office of Safeguards and Security for technical development and evaluation. A report by Pratt et al. on current technical developments of the first project appears elsewhere. ${ }^{6}$ This report covers the second project, neutron monitoring of plutonium storage vaults.

The ZPPR plutonium storage vault was selected as the site of the neutron monitoring experiment because of its typical plutonium inventory of fuel types (Table I), which produce neutron fields large enough to test the 
TABLE I

ISOTOPIC VALUES FOR FIVE TYPES OF PLUTONIUM FUELS STORED AT THE ZPPR FACILITY

\begin{tabular}{|c|c|c|c|c|}
\hline Fuel Alloys & $\begin{array}{c}{ }^{239} \mathrm{Pu} \\
(\%) \\
\end{array}$ & $\begin{array}{c}{ }^{240} \mathrm{Pu} \\
(\%) \\
\end{array}$ & $\begin{array}{c}{ }^{241} \mathrm{Pu} \\
(\%)\end{array}$ & $\begin{array}{l}{ }^{241} \mathrm{Am} \\
(\%) \\
\end{array}$ \\
\hline Pu-Al & 95.25 & 4.50 & 0.20 & 0.24 \\
\hline Pu-U-Mo & 90.80 & 8.66 & 0.51 & 0.46 \\
\hline Pu-U-Mo & 87.00 & 11.56 & 1.20 & 0.59 \\
\hline $\mathrm{Pu}-\mathrm{Al}$ & 74.20 & 22.23 & 2.86 & 1.80 \\
\hline $\mathrm{Pu}-\cup-\mathrm{Mo}$ & 68.70 & 26.40 & 3.39 & 2.19 \\
\hline
\end{tabular}

system adequately. In the vault, canisters of plutonium are stored in cubicles that form free-standing concrete walls (Fig. 1). Each cubicle can accommodate up to 24 canisters on six levels (Fig. 2). Most canisters contain no more than $3 \mathrm{~kg}$ of plutonium.

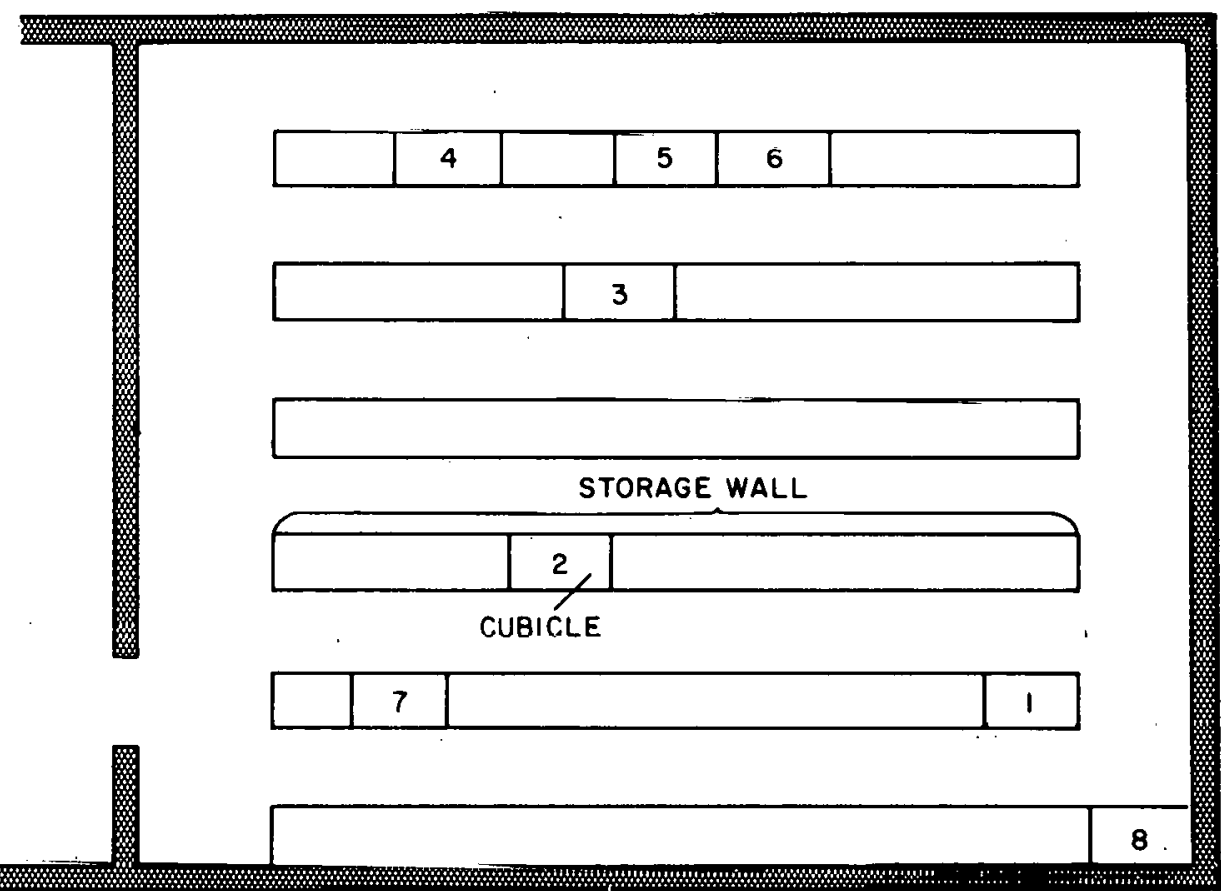

Fig. 1.

Location of cubicles used in the neutron monitoring experiments. 


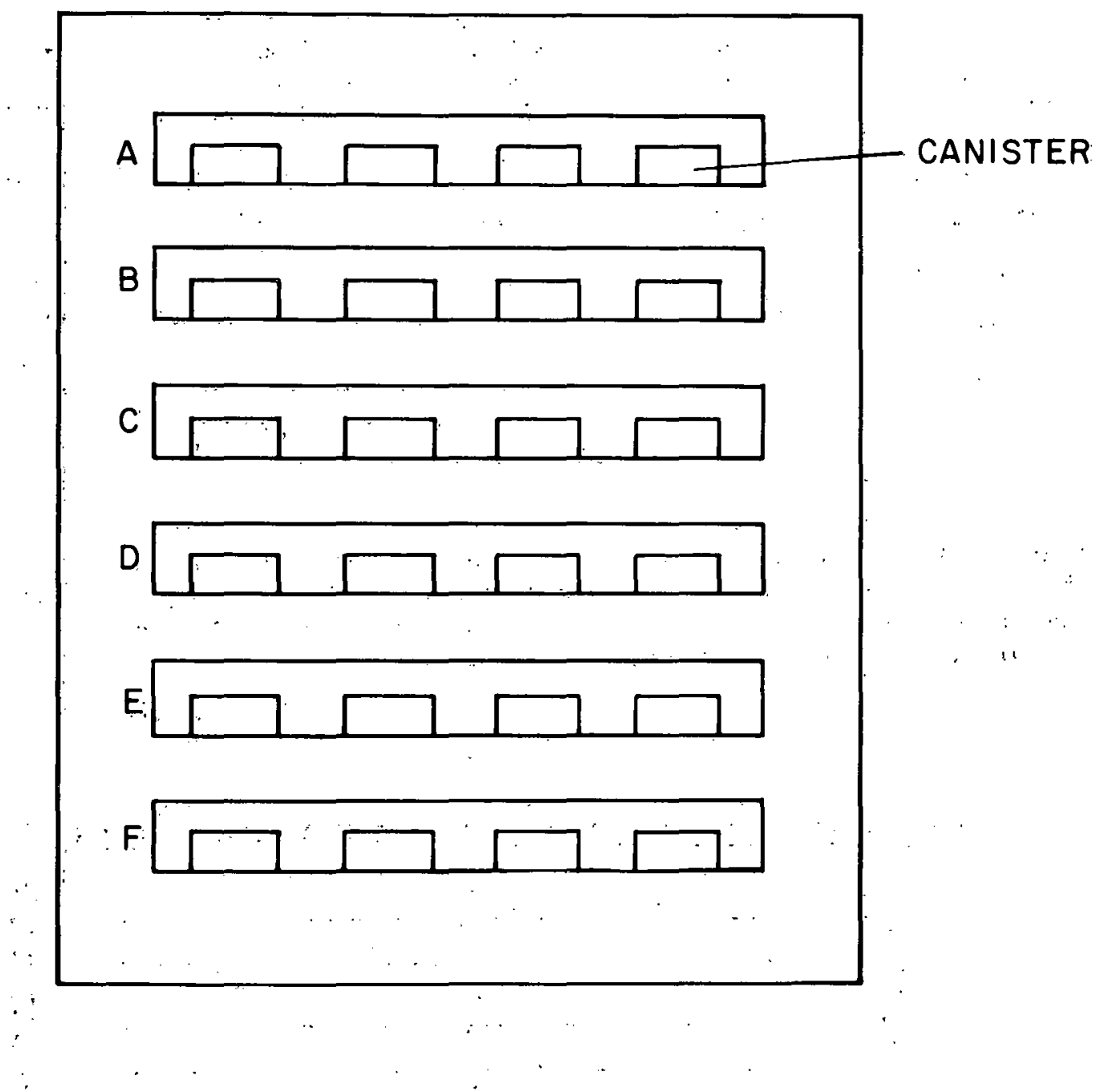

Fig. 2.

A concrete cubicle offers six levels of storage.

On our first trip to ZPPR, we performed preliminary measurements using a grid, of five ${ }^{3} \mathrm{He}$ proportional counters with modular, individual counting electronics and. sealer readouts that are commercially available. This equipment was used to determine gross count rates, crude removal sensitivities, and optimum neutron detector spacing required to maintain. overall detection sensitivity throughout the vault. After analyzing this information, we proposed the detector array shown in Fig. 3: a grid of 25 neutron detectors, each including. individual signal-conditioning and counting electronics, suspended from the vault ceiling. The detectors were to be connected to a data acquisition system located outside the vault. 


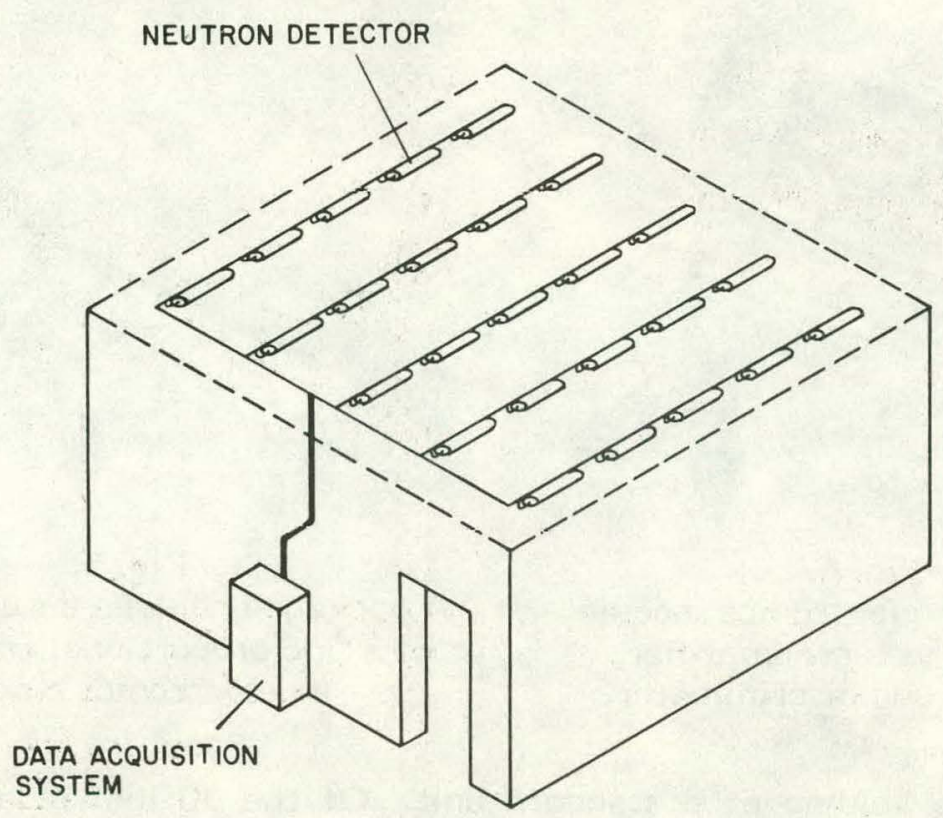

Fig. 3.

Installation of vault monitoring system in the ZPPR vault. The neutron detectors are suspended from the ceiling inside the vault, whereas, the data analysis equipment is installed outside the vault.

To our knowledge, no one had previously proposed such a comprehensive vault monitoring system. The proposal completed the initial phase of the study. ${ }^{7}$ At that time, we estimated that, with the 25 -detector array we could reliably detect $\pm 0.5 \%$ changes in the neutron count rate or roughly the removal of $5 \mathrm{~kg}$ of plutonium from a nominal $1000-\mathrm{kg}$ total inventory.

The next phase of the project consisted of solving two technical problems: (a) the availability of individual counting electronics for the detectors that were both reliable and inexpensive (because 25 sets were required) and (b) a data acquisition system capable of handling 25 simultaneous scaler inputs and performing on-line analysis of each.

We solved the problem of electronics for the individual ${ }^{3} \mathrm{He}$ proportional counters with an integrated circuit (IC) design (Fig. 4) that performed the electronic functions of preamplifier, amplifier, and discriminator. All the electronics were contained within a $15-\mathrm{cm}-$ long, 5-cm-diam package designed to mount directly onto the end of a single $5-\mathrm{cm}$-diam ${ }^{3} \mathrm{He}$ proportional counter. Figure 5 shows the electronics unit mated with a 5 -cm-dianl cuunter.

The circuit design relies on common IC chips and, thus, has relatively few individual electronic parts. The result is a low total cost for both components and assembly. Some 30 sets of electronics for the neutron detectors were assembled at Los Alamos for a unit cost of about \$350, which is almost an order of magnitude less than the price of a standard preamplifier, amplifier, and discriminator unit. Moreover, our assembled neutron detector occupies a 


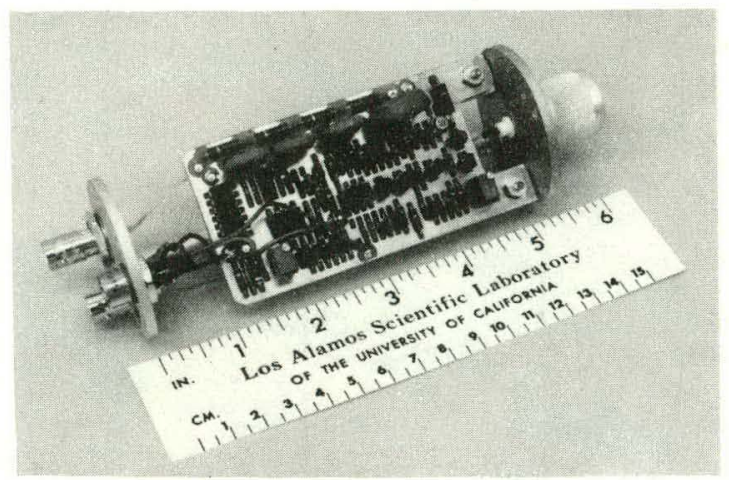

Fig. 4.

The compact electronics module functions as a preamplifier, amplifier, and discriminator.

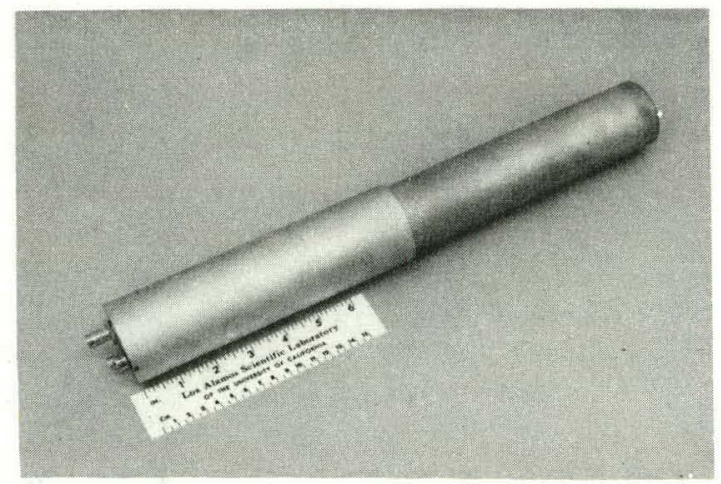

Fig. 5 .

A packaged neutron detector consists of a ${ }^{3} \mathrm{He}$ proportional counter and an electronics module.

fraction of the volume of a standard unit. Of the 30 individual electronics packages that were assembled at Los Alamos, 5 were reserved as spares.

The same circuit design has another use: it will be part of a large neutron detector system currently being built for the transuranic waste assay program, which provided a portion of the development costs for the design. The concurrent needs of the two programs made it possible for us to undertake the circuit design project.

A careful study of the problems of data acquisition, storage, analysis, and hard copy indicated that all project requirements could be met with a commercially available data acquisition system. We selected a LeCroy 3500 system because of its unique feature, a CAMAC minicrate. Five multiplescaler input modules resident in the minicrate could be used to acquire data from the 25 neutron detectors in real time, with negligible deadtime losses for total count rate up to and exceeding $50 \mathrm{kHz}$.

The complete vault monitor set of 25 neutron detectors, each consisting of a ${ }^{3} \mathrm{He}$ counter mated with an electronics module is shown in Fig. 6, with required cabling, as it appeared during the test and checkout phase at Los Alamos. The entire monitoring system was in operation at the time the photograph was taken.

After assembling the complete vault monitoring system at Los Alamos, we spent 6 weeks checking it out. In addition to correcting some minor hardware malfunctions, we developed specific computer programs to provide acquisition, analysis, hard copy, and disk storage of all data.

Following the Los Alamos checkout phase, we requested permission from Argonne and the DOE Chicago Operations Office to install the monitoring system in the ZPPR plutonium storage vault for an extended measurement and evaluation program. Permission was granted and in April 1980 we took the equipment to Idaho and installed it. Figure 7 shows the arrangement of the detector packages in the vault and the LeCroy data acquisition system located outside. The detectors were mounted in existing unistrut grooves $2.4 \mathrm{~m}$ above 


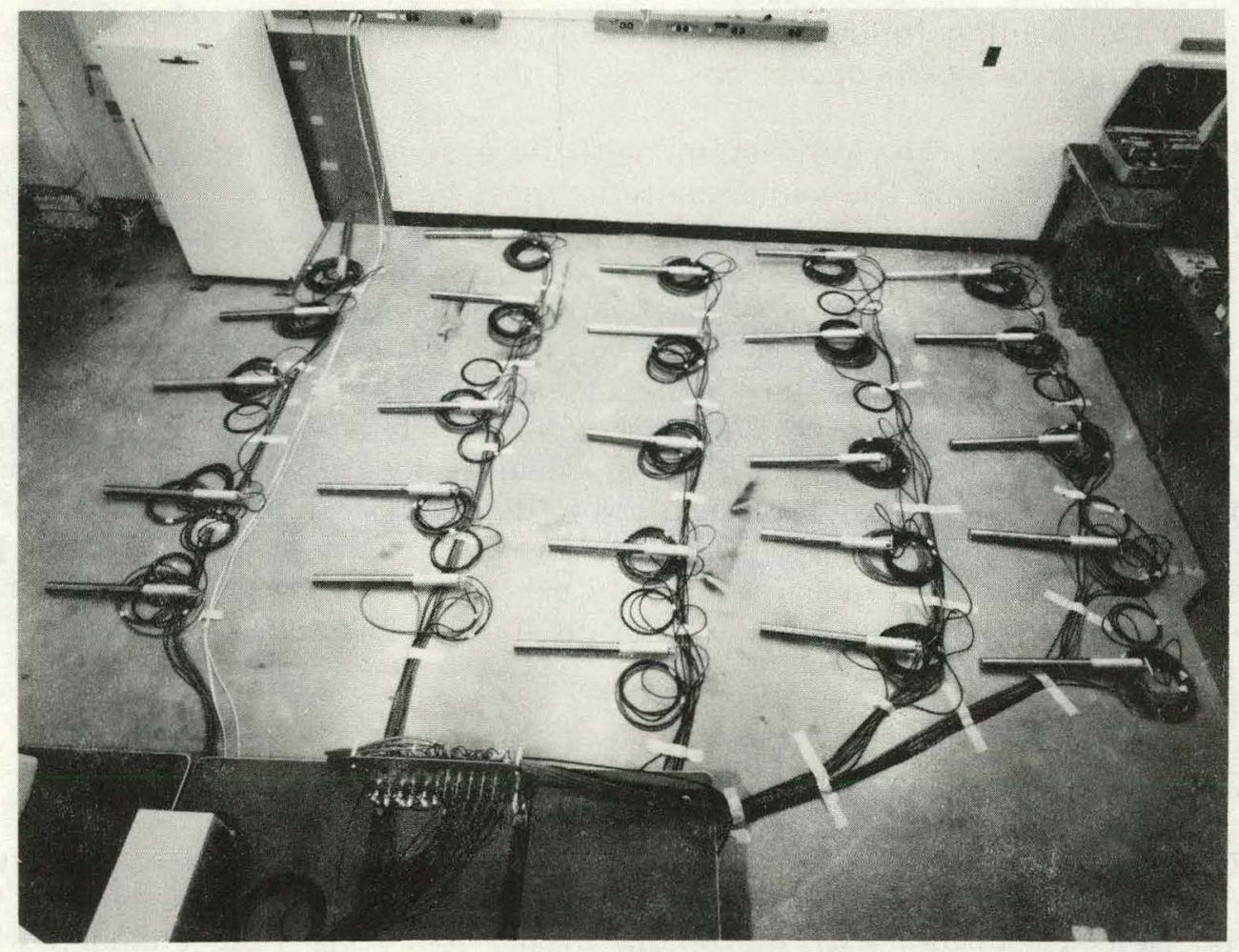

Fig. 6.

Test configuration of the 25 neutron detectors at Los Alamos.

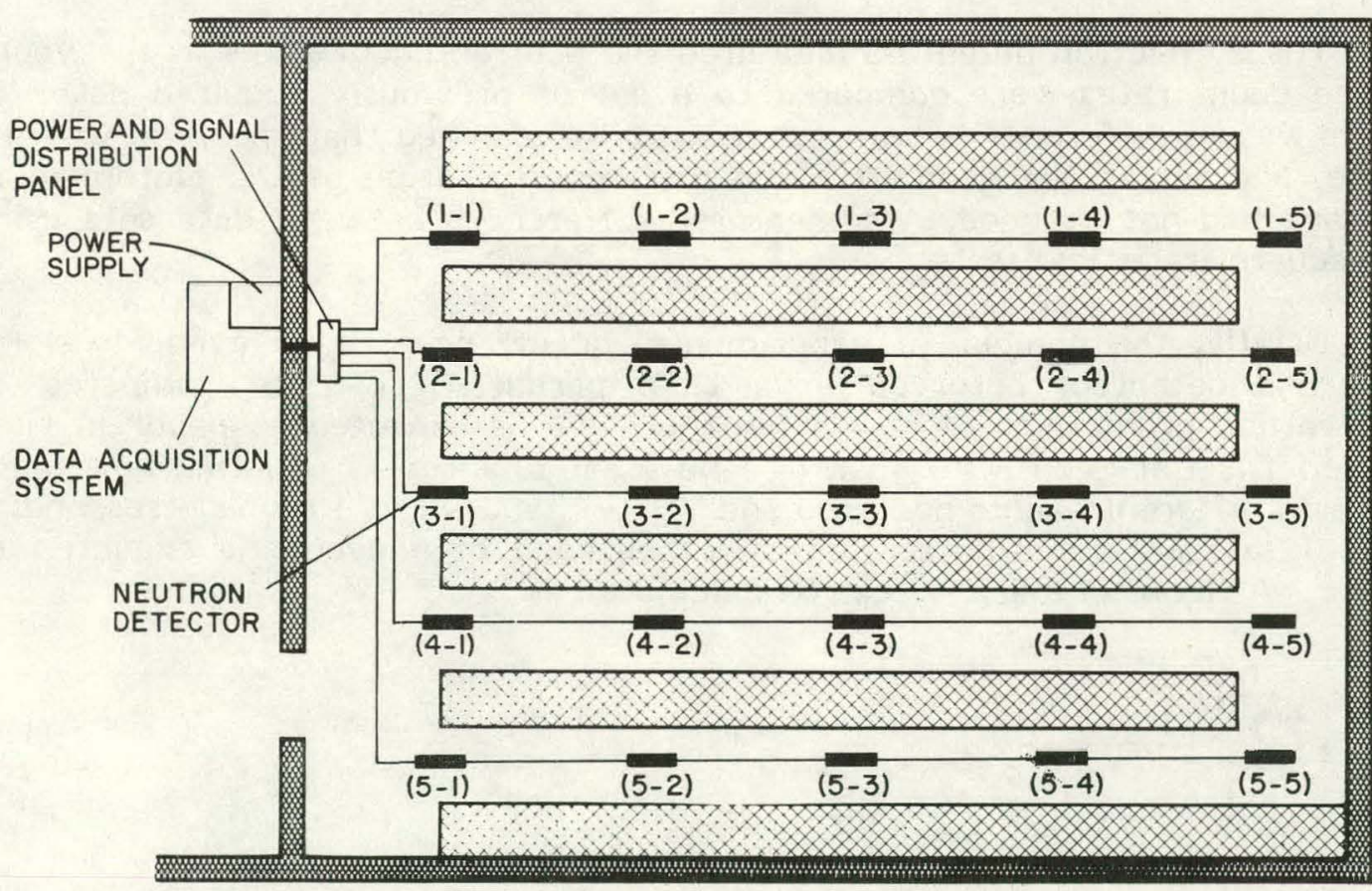

Fig. 7.

Neutron detector placement in the ZPPR vault. Each detector is identified by aisle and position from the front of the vault. 
the floor; the cabling followed existing ceiling structures to minimize interference with normal vault operations. ${ }^{4}$

The installed monitoring system, with data acquisition and power supply systems located outside the vault, caused almost no disruption to normal vault operations. The one exception was that sensitivity measurements of the neutron field for plutonium removal experiments required the assistance of vault custodians in removing canisters from specific cells.

The ZPPR phase of the project extended from April 1 through December 2, 1980. During this 8-month period, data was recorded almost continuously, with the exception of brief down periods associated with power outages or power line surges that resulted in dead stops of the data acquisition system. Installation of a power filter in June eliminated the line surges. For the period October-December, the monitoring system ran continuously. In December, we disassembled the entire vault monitoring system and brought it back to Los Alamos.

\section{STATISTICS USED FOR DATA ANALYSIS}

The experimental setup of neutron detectors and the data acquisition system at ZPPR were used to measure statistically significant changes in the neutron field associated with plutonium in storage. The field changed when the spatial distribution of the plutonium was disturbed. One objective of our research was to determine the smallest amount of removed plutonium that we could detect with reasonable confidence, using a manageable number of detectors.

The 25 neutron detectors measured the neutron count rates in the vault. These count rates were compared to a set of previously acquired data. If there was no difference between data sets, we assumed that the field was the same, and hence, the geometric and mass configuration of the plutonium in storage had not changed. We measured differences between data sets using chi-square statistical tests.

Briefly, the number of experimental occurrences of an event (such as neutrons detected) observed in a time period $T_{c}$ can be compared to theoretical predictions of how often the event is expected to occur in tirne period $T_{c}$. Let $U=\left\{u_{1}, u_{2}, \ldots, u_{n}\right\}$ be a set of integers denoting how many times $n$ different events occurred and $V=\left\{v_{1}, v_{2}, \ldots, v_{n}\right\}$ be a corresponding set of integers denoting how many times each of $n$ events is expected to occur. A figure of merit $\chi_{a}^{2}$ can be calculated as

$x_{a}^{2}=\sum_{i=1}^{n} \frac{\left(u_{i}-v_{i}\right)^{2}}{v_{i}}$ 
The probability that $x^{2}<\chi_{a}^{2}$ is described as

$P\left(x^{2}<x_{a}^{2}\right)=\int_{0}^{x_{a}^{2}} P_{(n-1)}\left(x^{2}\right) d x^{2}$,

where

$P_{(n-1)}\left(x^{2}\right)=Y_{0} X^{n-3} e^{-X^{2} / 2} \quad$.

The expression $p_{n-1}\left(\chi^{2}\right)$ is also called the probability density function of the $X^{2}$ distribution with $(n-1)$ degrees of freedom. $Y_{0}$ is a constant that causes the integral of Eq. (2) to be unity when limits of zero and infinity are used. By selecting probability thresholds, one can state that certain small differences are statistically significant, or insignificant, at a certain confidence level based on the value calculated for $x_{a}^{2}$. Thus, if

$0.001<P\left(X^{2}<X_{a}^{2}\right)<0.999$

is chosen as the probability window required for a valid comparison, where changes in frequencies are statistically insignificant, only two comparisons per thousand will produce a false alarm. A low false-alarm rate is an important operational constraint.

Because it was desirable to compare two observed sets of neutron count data that were collected over unequal counting time periods, Eq. (1) can be modified as follows, such that $\chi_{a}^{2}$ is calculated in terms of count rates and counting times:

$$
x_{a}^{2}=\sum_{i=1}^{n}\left(u_{1 i}-u_{2 i}\right)^{2} /\left(\frac{u_{1 i}}{t_{c}}+\frac{u_{2 i}}{t_{c}}\right),
$$

where $U_{1}=\left\{u_{11}, u_{12}, \ldots, u_{1 n}\right\}$ and $U_{2}=\left\{u_{21}, u_{22}, \ldots, u_{2 n}\right\}$ are two sets of neutron count rates observed over counting times $t_{c_{1}}$ and $t_{c_{2}}$. All data sets of neutron count rates were-subjected to $x^{2}$ comparisons with other data sets in the experiments described in Sec. VI.

The total count rate accumulated by all the detectors is also an indication of plutonium removal, although this parameter is not as sensitive as the $x^{2}$ criteria hecause it does not measure the distortion in the shape of the neutron field. Consider a set of observed count rates from $n$ detectors

$U=\left\{u_{1}, u_{2}, u_{3}, \ldots, u_{n}\right\} \quad$.

Each kilogram of plutonium in storage can be thought of as contributing to the total count rate $\left(\sum_{i=1}^{n} u_{i}\right)$. Thus, changes in the total count rate are indicative of changes in the mass of plutonium in storage. The total count ratc $C_{R}$ can be expressed as 
$C_{R}=\sum_{i=1}^{n} u_{i}$

whereas the total number of counts observed $\mathrm{C}_{T}$ is

$C_{T}=C_{R^{t}}$,

where $t_{c}$ is the counting time. An uncertainty in $C_{T}$ exists and its standard deviation is defined by $\left(C_{T}\right)^{1 / 2}$. Thus the total count rate has $1-\sigma$ brackets as follows:

$c_{R}=\sum_{i=1}^{n} u_{i} \pm\left(t_{c} \sum_{i=1}^{n} u_{i}\right)^{1 / 2} / t_{c}$.

Consider the case of 25 detectors with a total count rate of $50000 \mathrm{~Hz}$ produced by $2500 \mathrm{~kg}$ of stored plutonium. Each kilogram of plutonium would account for approximately $20 \mathrm{~Hz}$ of the rate, on the average. If the array of 25 detectors were allowed to count for $200 \mathrm{~s}$, the total count rate would be $50000 \pm 15.8 \mathrm{~Hz}$. At the $1-\sigma$ level, the statistical uncertainty in the total count rate is the same as that count rate change caused by removal of $1 \mathrm{~kg}$ of plutonium. Clearly, extended counting times and highly stable electronics in the detectors are required to detect the removal of $1-\mathrm{kg}$ amounts of plutonium.

\section{DATA ACQUISITION EQUIPMENT AND SOFTWARE}

A LeCroy 3500 data acquisition system processes data from the 25 neutron detectors (Fig. 8). The LeCroy is a special-purpose microcomputer with powerful data acquisition and computational facilities. It is based on an Intel 8085 8-bit central processing unit with a dual floppy disk system for secondary storage. Input and output are performed by three peripheral devices: an alphanumeric and graphics display, a keyboard, and a character printer.

The LeCroy interfaces with scientific experiments by means of an eight-slot CAMAC minicrate. The minicrate accommodates standard CAMAC modules and, thus, can both acquire data from a scientific experiment as well as control the experiment. For the ZPPR experiments, we used six Kinetic Systems* 3610 hex scalers and one Kinetic Systems 3061 input gate/output register (IGOR) as the interface between the LeCroy and the experiment.

Data acquisition and processing took place as follows. Original ${ }^{3} \mathrm{He}(n, p)$ reaction pulses from each detector passed through a set of separate

\footnotetext{
* Kinetic Systems Corp, subsidiary of Kinetic Systems International, Mary Knoll Dr., Lockport, IL 60441.
} 


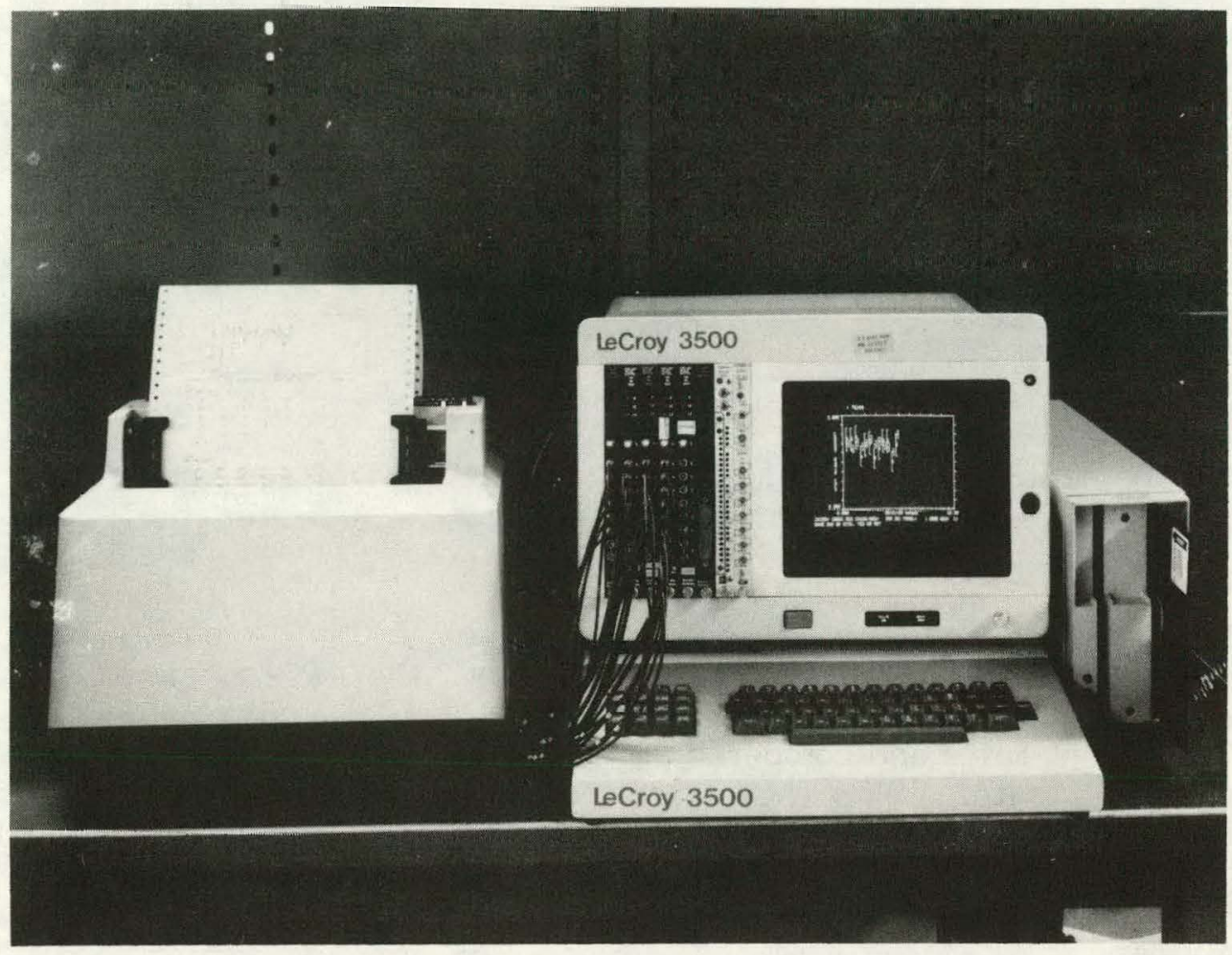

Fig. 8.

The LeCroy 3500 is a special-purpose microcomputer with powerful data acquisition and computational facilities.

signal-conditioning electronics that converted them to standard transistorto-transistor logic (TTL) pulses (Fig. 9). These logic pulses were fed to the 25 separate counters, housed in five Kinetic Systems 3610 hex scalers (see Fig. 10), whose counting times were controlled by a single input gate/output register. The LeCroy controlled the scalers by an eight-slot CAMAC minicrate that interfaced with the system bus, the Multibus. A $1.000-\mathrm{kHz}$ crystal-controlled signal was dirested to an additional counter to provide accurate timing for processing the neutron signals. Information pertaining to neutron counts and count rates could then be acquired and analyzed by application programs written for the LeCroy.

These application programs were developed using the system software tools that came with the LeCroy 3500: CPM (control program/ microprocessor) operating system, FORTRAN compiler, symbolic assembler, CAMAC library, plotting library, symbolic editor, and linking loader. Two primary application programs were written to operate in real time. The VAULT program processed data from removal experiments; the VLONG program processed data from stability experiments. Additional application programs were developed to process previously acquired data.

Program VAULT acquired data for removal experiments in which certain amnunts of plutonium were removed from known locations in the vault. Measurements of the neutron field were made before and after the remuvals. VAULT directed the neutron detectors to count for a nominal time, usually 50 


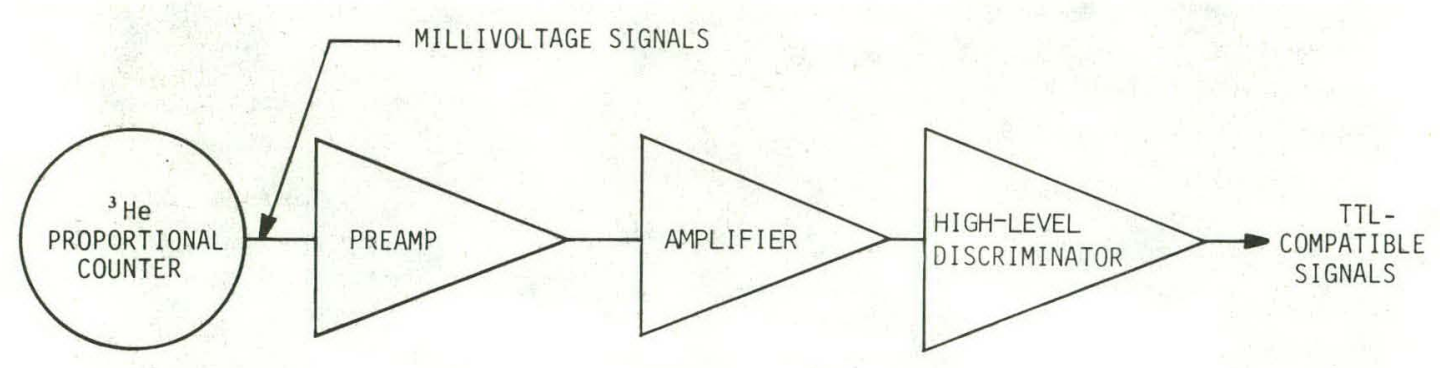

Fig. 9.

The neutron detector electronics convert millivoltage signals to TTL-compatible signals.

to $500 \mathrm{~s}$, as specified by the operator. At the end of a count, the data accumulated from each detector were read into the LeCroy along with the count time. Then the LeCroy calculated total counts, total count rates, and individual count rates and compared previously collected sets of data with the current set of data. Using the LeCroy, we made a $\chi^{2}$ comparison for the current data and displayed the appropriate statistical quantities, which include $x^{2}, x^{2}$ per degree of freedom, and sigma deviation for each detector. The newly acquired data could then be saved on diskettes for future comparisons or analyses.

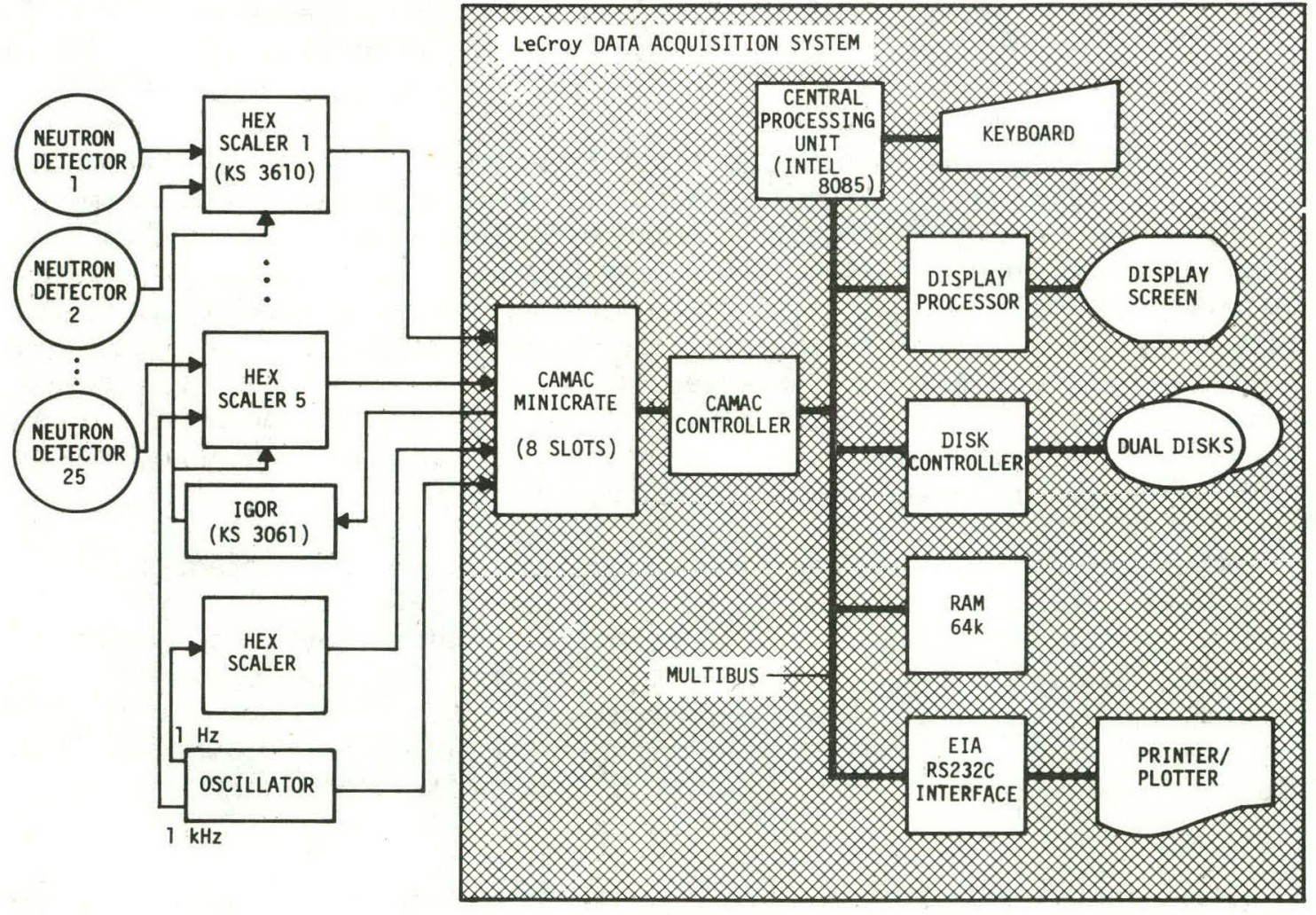

Fig. 10.

Signal-processing in the vault monitoring system. 
Program VLONG acquired data for stability experiments, which ran over long periods of time when no activity occurred in the vault. These experiments identified long-term drifts or stability of the equipment used to collect and process the data. VLONG directed the neutron detectors to count for a specified period of time, usually from 500 to $2000 \mathrm{~s}$. The data from the detectors were read into the LeCroy for a comparison with previously acquired data. The probability for the $x^{2}$ value thus acquired was determined from a table. If the probability was less than 0.001 or greater than 0.999 , the total count, the total count rates, and the individual counts for each set of data were printed on the character printer along with the $x^{2}$ information. The newly acquired data set was saved on a diskette to be compared with subsequently acquired data sets.

When the newly acquired data set had a $\chi^{2}$ whose probability was within the 0.001 - 0.999 probability limit, the data were discarded and another collection cycle started. The $x^{2}$ data were accumulated in a histogram that represented the probability density of the chi-squares actually observed from all the comparisons made by VLONG. This observed probability density function was overlaid with the theoretical $\chi^{2}$ probability density function so that the validity of the statistics for the collected data could be verified. To terminate VLONG's execution, an operator would throw a front panel switch, which displayed the final value of the $\chi^{2}$ histogram on the video screen and printed it on the character printer.

We re-examined previously collected data because original results were sometimes obscured hy an unstable detector. Several programs were written to recalculate the analyses of VLONG and VAULT with the option to eliminate certain detectors from the computation. Eliminating one or two obviously unstable detectors from an analysis allowed us to investigate more subtle long-term system drifts.

\section{IMPROVEMENTS TO SYSTEM PERFORMANCE}

The ZPPR measurements included 82 stability experiments, some of which ran for more than 1 week, and 16 removal experiments. In addition to the experiments, we adjusted the detectors, replaced high-voltage power supplies, and repaired other equipment failures. For example, we determined that the original high-voltage power supply for the neutron detectors lacked sufficient regulation. We replaced it with another, more highly regulated power supply that improved high-voltage constancy by a factor of 10 . This led to much greater detector stability, which, in turn, allowed longer counting runs that greatly improved the quality of the stability experiments. Most of the experiments discussed in Sec. VI took place after replacement of the power supply.

Based on previous experience with reasonably large ${ }^{3} \mathrm{He}$ proportional counter systems, we initially expected to achieve a $\pm 0.5 \%$ count rate stability for the monitoring system. Data used for the long-term stability studies were gathered during times when the vault was secured, usually overnight or on weekends. The $\pm 0.5 \%$ level of stability was, in fact, achieved from the start of the ZPPR measurements. Figure 11 shows a typical count rate record obtained during the evening and early morning hours of June 18-19. The record covers a $13-h$ counting period and shows the summed count rate from 
all 25 detectors on a greatly expanded scale: The full vertical scale covers the count rate range from 51720 to 52040 counts/s, or a $\pm 0.3 \%$ variation from the mean count rate. The actual excursions observed were even somewhat less than $\pm 0.3 \%$; typically we recorded count rate stability values of $\pm 0.25 \%$ for overnight and weekend runs, that is, during such periods when no power outages or surges occurred. This represented a factor of 2 better stability than we had initially expected and corresponds roughly to a detection capability of $2.5 \mathrm{~kg}$ of plutonium removed from a $1000-\mathrm{kg}$ vault inventory.

However, detailed examination of the count rate histories of individual detectors revealed that most of the drift typified by the Fig. 11 record was, in fact, attributable to relatively large fluctuations in just a few detectors. Subsequent tests also showed that the single high-voltage power supply used to provide anode high voltage to all 25 detectors was undergoing small but significant high-voltage output drifts, generally on a diurnal cycle and in apparent response to slight room temperature variations.

On October 15, we decided to make a significant improvement in system stability beyond that already demonstrated. We obtained a highly stable high-voltage power supply (with a high-voltage stability 10 times better than the first supply) and installed it at ZPPR. At the same time we rechecked all electronics units; those in apparent need of adjustment were either trimmed for gain and threshold or replaced with a spare unit.

The resultant system stability appears in Fig. 12, a typical 18-h record obtained during the evening and early morning hours of December $1-2$. The full vertical scale range here is 50600 to 50920 counts/s, or a $\pm 0.3 \%$ variation from the mean count rate. The marked periodic fluctuations are apparent and curious, to say the least. However, the overall experimental count rate

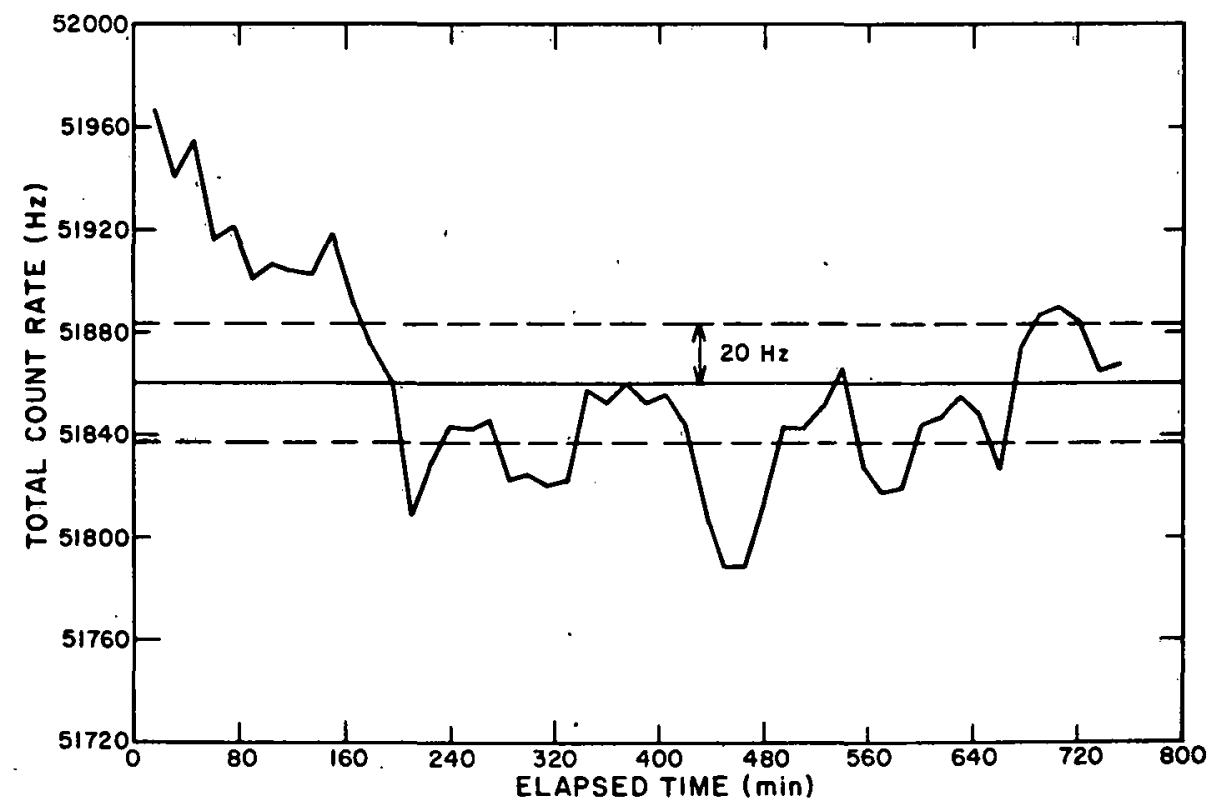

Fig. 11 .

Count rate record for stability experiment conducted on June 18-19 using all detectors for $800 \mathrm{~min}$.

Results fall within a $20-\mathrm{Hz}$ error band. 


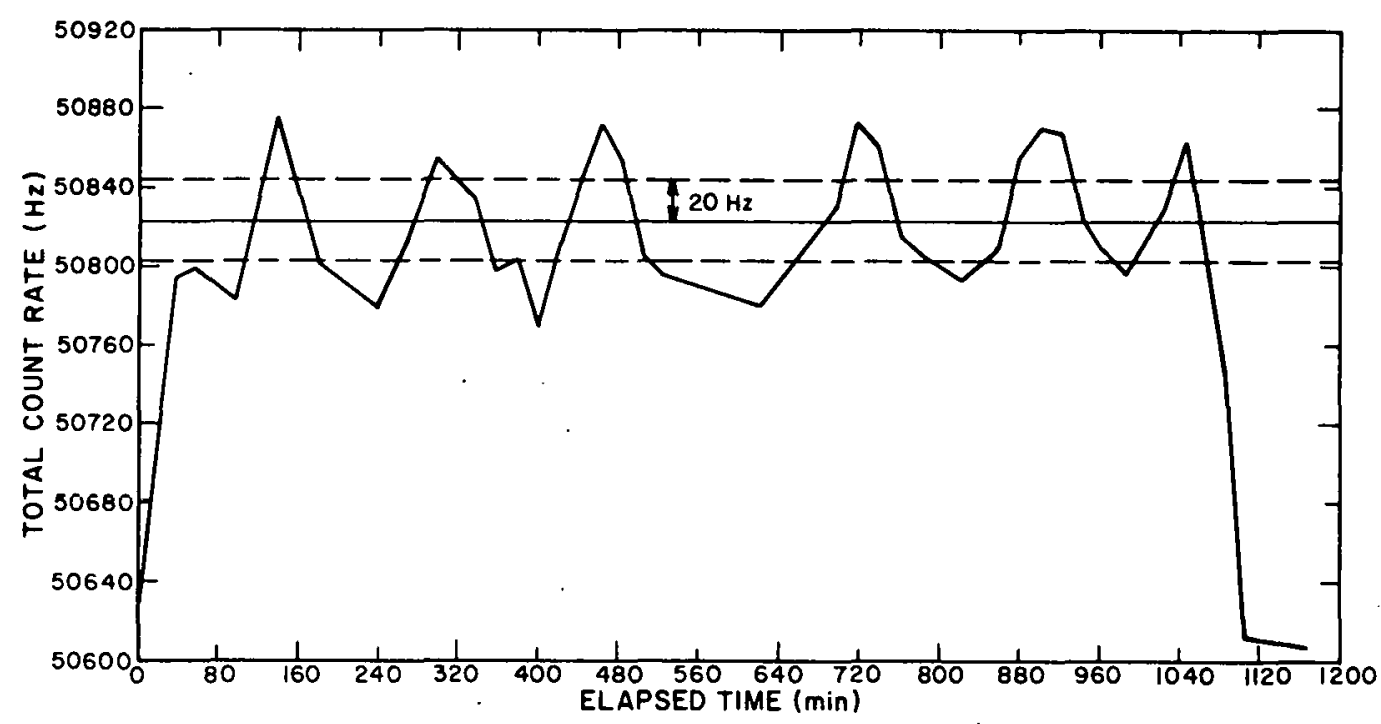

Fig. 12.

Count rate record for stability experiment conducted on December $1-2$ using all detectors for 1100 min. Results fall within a $20-\mathrm{Hz}$ error band.

stability obtained here is about $\pm 0.12 \%$, a considerable improvement. An examination of the count rate histories of individual detectors indicated that almost all the observed fluctuation was associated with detector (4-2).

Figure 13 plots the same data shown in Fig. 12 with the contribution from detector (4-2) removed from the data set. That is, Fig. 13 is a stability record of the set of 24 detectors from which detector (4-2) has been excluded. This plot shows a count rate stability of $\pm 0.04 \%$, a close approximation to the expected fluctuation pattern for purely statistical fluctuations. (The low values at the beginning and end of the plots in Figs. 12 and 13 are caused by neutrons escaping from the vault when the door was open. The stability study began shortly before the vault was closed for the night and ended the next day after it was reopened.)

Figure 14 shows data from another stability experiment, with contributions from detector (4-2) removed, for a 65-h continuous monitoring period starting on November 26. The fluctuation band in the figure again spans a $\pm 0.04 \%$ range. This record and almost all other records taken after the high-voltage power supply was replaced display similar results. We must report, however, some transient disturbances that occurred during a few of these monitoring periods. We do not completely understand these disturbances at this time, but they appear to be associated with line power fluctuations that penetrate the filter unit and disrupt the digital counting electronics.

Our study of the count rate stability for the vault monitoring system was based on system stability records for 24 detectors taken over a period of 2 months during which no system maintenance was performed. The study clearly implied that neutron monitoring of a plutonium storage vault could be 


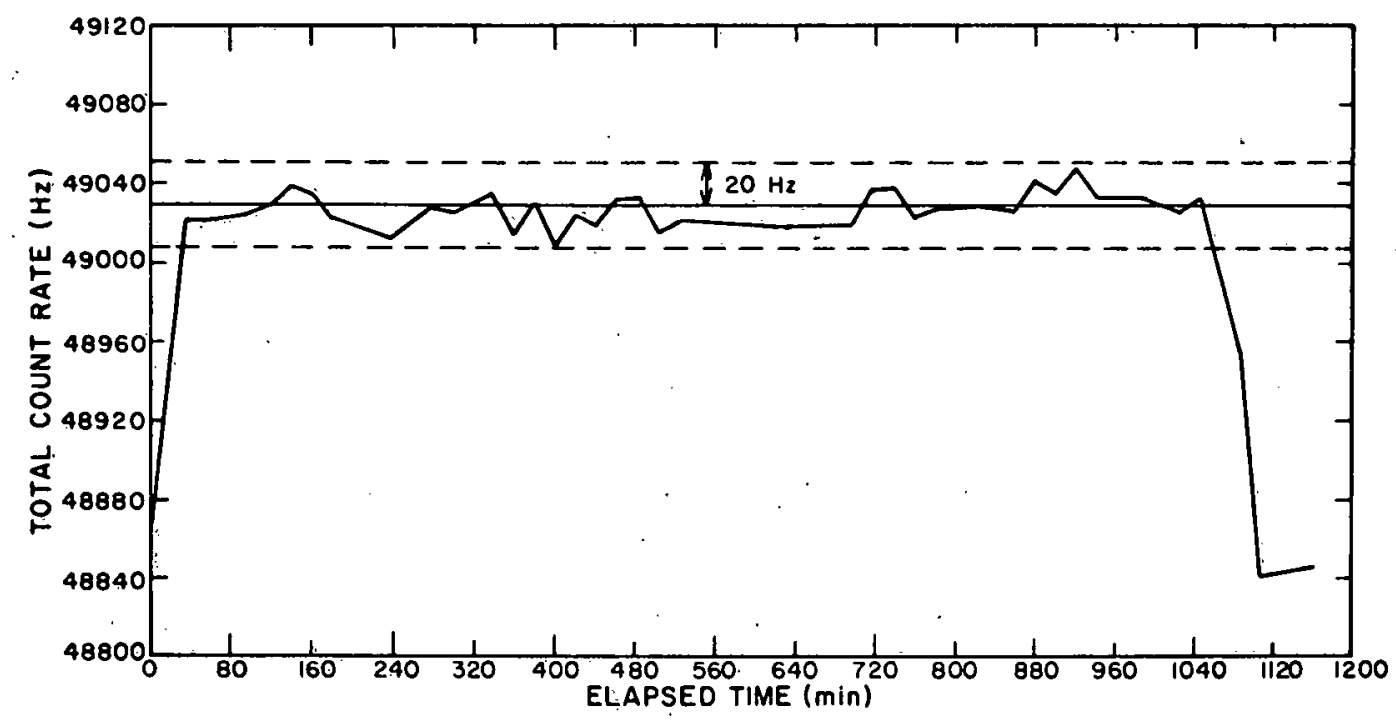

Fig. 13.

Count rate record for stability experiment conducted on December 1-2, with detector (4-2) removed, for $1.100 \mathrm{~min}$. Results fall within a $20-\mathrm{Hz}$ error band.

done at the \pm 0.04 to $\pm 0.05 \%$ stability level or a factor of 10 better than our initial projections. Thus, it appeared possible to detect plutonium removals on the order of $1 \mathrm{~kg}$ from a vault whose total inventory, was $2500 \mathrm{~kg}$.

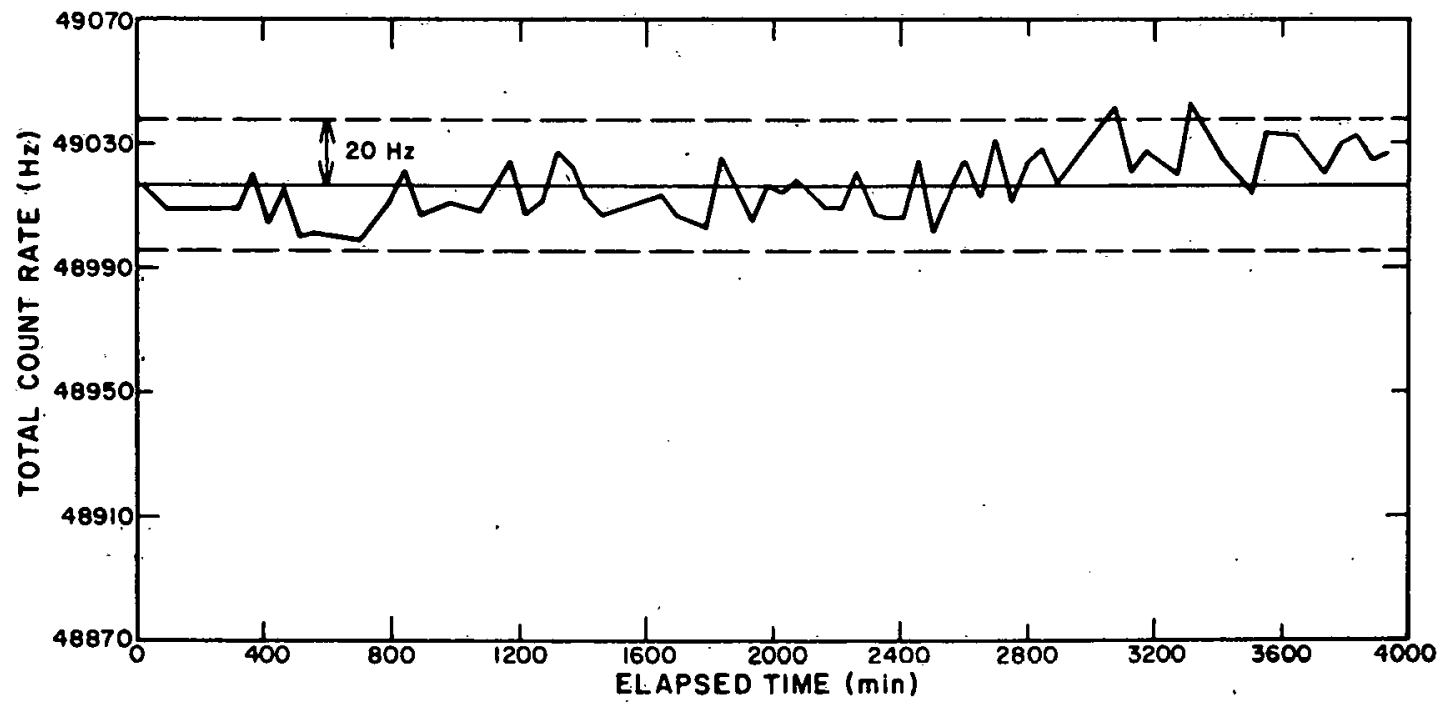

Fig. 14.

Count rate record for stability experiment conducted on November 26, with detector (4-2) removed, for $4000 \mathrm{~min}$.

Results fall within a $20-\mathrm{Hz}$ error band. 


\section{PLUTONIUM REMOVAL EXPERIMENTS}

The vault monitoring system was in its most stable configuration after October 15, when the high-voltage power supply was replaced. Hence the most reliable data were acquired after that date. To present our best data first, we shall begin our discussion of removal experiments in reverse chronological order, starting with those that were performed in December and November and then reporting those that took place in July and June. The earlier data were adversely affected by instabilities in the power supply. Results before and after the replacement can be compared.

Sixteen direct measurements of plutonium removal were performed during the 8 months the monitoring system was installed in the. ZPPR vault. The measurements, which detected the vault neutron field, were performed in the following manner. We selected a cubicle in which every location contained four canisters of plutonium and mace a background measurement. Then we removed two canisters, each containing approximately $3 \mathrm{~kg}$ of plutonium, from level $A$ (the top level) and made another measurement, after which we replaced the canisters. Next we removed two canisters from level $B$ and measured the field. We tested every level in the cubicle in this manner.

Another method we used was to add approximately $6 \mathrm{~kg}$ of plutonium to certain levels. The information obtained from these addition experiments supplemented the removal data.

We discovered that small distortions in the neutron field could be detected. Such distortions were caused by persons moving in the vault, the vault door being open, or removed material located too close--less than $3 \mathrm{~m}$--to the vault entrance. Thus, all subsequent measurements were made with no one in the vault, the door closed, and all removed material stored about $10 \mathrm{~m}$ away and shielded by concrete walls during measurement of the neutron field. Program VAULT acquired data during the measurements to produce pages of output similar to the one shown in Fig. 15.

Results of the December 2 removal experiment appear in Table II. In this experiment, we removed $6 \mathrm{~kg}$ of $26 \%{ }^{240} \mathrm{Pu}$ from cubicles $5 \mathrm{C}$ and $6 \mathrm{C}$ and measured the background. Then we inserted these $6 \mathrm{~kg}$ of plutonium successively in the levels specified in Table 11 and made measurements. The insertions were made at the top, middle, and bottom of cubicle 3 . The count rate for removing $6 \mathrm{~kg}$ of plutonium changes by almost $600 \mathrm{~Hz}$ when the plutonium is removed from the top level of the cubicle, whereas only a $210-\mathrm{Hz}$ difference is noted for material removed from the bottom level. Count rates per kilogram of $26 \%{ }^{240} \mathrm{Pu}$ vary from $98 \mathrm{~Hz}$ for the top level to $35 \mathrm{~Hz}$ for the bottom level.

Measurements of typical canisters of $26 \%{ }^{240} \mathrm{Pu}$ and $11 \%{ }^{240} \mathrm{Pu}$ indicate that the $26 \%$ material emits 2.5 as many neutrons as the $11 \%$ material. Thus, the change in count rate $\Delta C_{R}$ per kilogram of $11 \%{ }^{240} \mathrm{Pu}$ can be computed from the $26 \%{ }^{240} \mathrm{Pu}$ data. A field distortion parameter

$K=\chi^{2} / \Delta C_{R}$ 


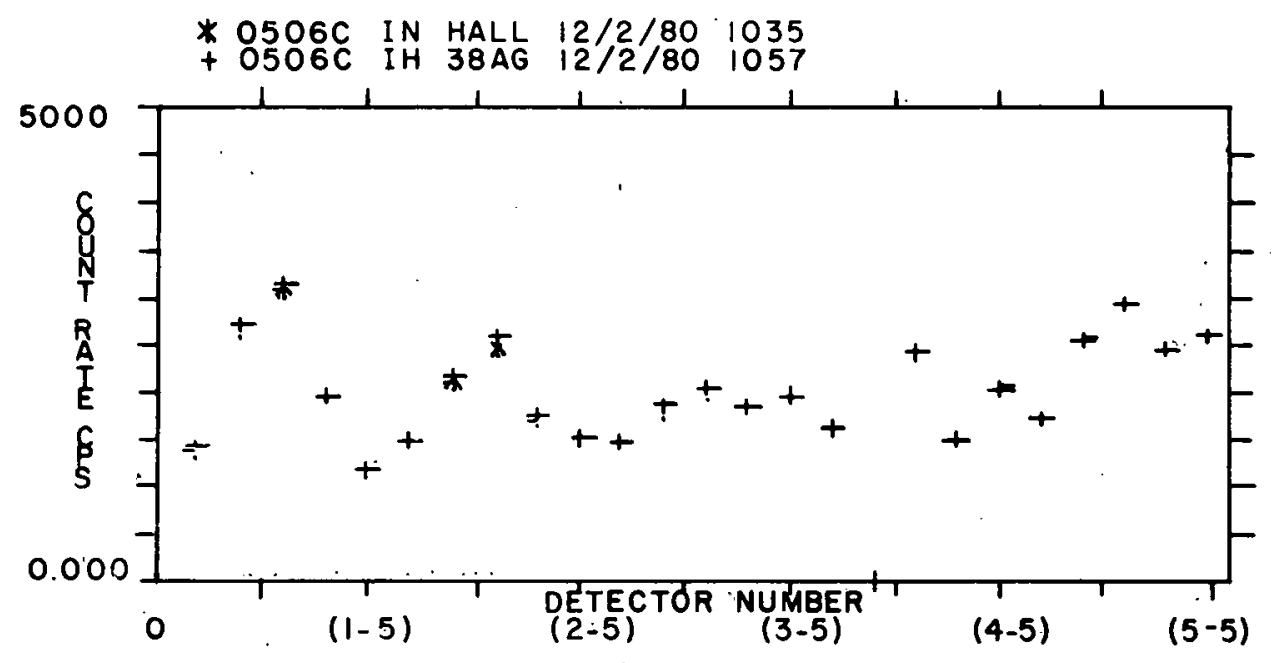

0506C IN HALL 12/2/80 1035

RUN TIME $(S E C)=501.167$

696868. 1358301. 1553960. 985703. 593312.

745901. 1064501. 1226284. 871174. 748953.

738431. 938637. 1019722. 929865. 982964.

812812 . $0.1212993 . \quad 744606.1018579$.

866176. 1269084. 1467903. 1225964. 1296770.

0506C IN 38AG 12/2/80 1057

RUN TIME $($ SEC) $=501.160$
702982. 1372268. 1573999. 994584. 598737.
755796. 1090232. 1304269. 888613. 759392.
745256. 949046. 1034468. 936606. 987534.
$817116 . \quad 0.1226514 .750622$. 1023860.
869335. 1277356. 1473758. 1229924. 1301584.

$$
\begin{aligned}
& \mathrm{CHISQ}=3729.319 \quad \mathrm{CHISQ} / \mathrm{NDG}=162.144 \quad \mathrm{PROB}=1.0000 \quad \mathrm{NOG}=23
\end{aligned}
$$

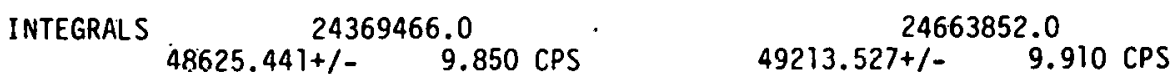

$$
\begin{aligned}
& \text { BIGGEST CHANGE AISLE } 2 \text { DETECTOR } 349.034 \text { SIGMAS } \\
& \text { COUNT RATE CHANGE IN SIGMAS }
\end{aligned}
$$

$\begin{array}{rrrrr}-5.176 & -8.464 & -11.343 & -6.321 & -4.976 \\ -8.083 & -17.539 & -49.034 & -13.155 & -8.508 \\ -5.612 & -7.586 & -10.299 & -4.944 & -3.265 \\ -3.380 & 0.000 & -8.668 & -4.928 & -3.705 \\ -2.407 & -5.195 & -3.426 & -2.538 & -2.998\end{array}$

Fig. 15.

Typical output from program VAULT. This printout shows removal sensitivity for $2.2 \mathrm{~kg}$ of $26 \%{ }^{240} \mathrm{Pu}$ with detector (4-2) set to zero. 
that indicates a change in the shape of the neutron field is also tabulated in Table II. K appears to be approximately 6 at the top of cubicle 3 and less than 3 at other levels.

We analyzed the December 2 removal data, excluding data taken by detector (4-2) because it was less stable than the others. The results appear in Table III. The instability of the one detector had little effect on the overall results of the experiment, as a comparison of Tables II and III reveals.

Table IV shows the results of the July 22 removal experiment in which we removed $6 \mathrm{~kg}$ of $26 \%{ }^{240} \mathrm{Pu}$ from cubicles $5 \mathrm{C}$ and $6 \mathrm{C}$ and measured the background. Then we inserted these $6 \mathrm{~kg}$ of plutonium successively into the six levels of cubicle 2, as shown in Table IV, and measured the count rate. The changes in total count rate varied from a high of 809 counts/s at the top of the cubicle to a low of 427 counts/s at the bottom. The field distortion parameter $K$ is 7.8 at the top and 2.5 to 3.0 at the other levels. The total count rate change per kilogram of $26 \%{ }^{240} \mathrm{Pu}$ removed varies from 135 to $71.2 \mathrm{~Hz}$ for the top and bottom levels of the cubicle, respectively, which corresponds to a removal sensitivity of 54 to $28 \mathrm{~Hz} / \mathrm{kg}$ for $11 \%{ }^{240} \mathrm{Pu}$.

Preceding the July 22 removal experiment, we fine tuned certain detectors and the high-voltage power supply to minimize instabilities in the system. Removal experiments performed on June 19 and 20 are summarized in Tables $V$ and VI, respectively. In the June 19 experiments, we removed $6 \mathrm{~kg}$ of $11 \%{ }^{240} \mathrm{Pu}$ successively from the six levels of cubicle 4 and then replaced it $3 \mathrm{~kg}$ at a time, making measurements for each of the mass configurations. In the June 20 experiment, we removed $3 \mathrm{~kg}$ of $11 \%{ }^{240} \mathrm{Pu}$ from the A level of cubicles 1 and 7 and then replaced it $3 \mathrm{~kg}$ at a time, first in cubicle 7 and then in cubicle 1. Next we removed plutonium and replaced it in like manner for levels $B, C, D, E$, and $F$ of these cubicles and took measurements at all the different mass configurations.

Although subsequent removal experiments were made using 500-s data acquisition times, the June 19 and 20 experiments ran $200 \mathrm{~s}$. Two factors (not present in Llie July 22 and December 2 experiments) affect the quality of the data in the .June experiments: (a) length of the data acquisition times and (b) stability of the detectors and high-voltage power supply. In Table $V$ the total count rate column shows a fluctuation, with all 24 canisters of plutonium present in the cubicle, that varies from 51922 to 51811 counts or about seven standard deviations. Table VI shows similar variations in total count rate. Thus, numbers for $\chi^{2}$ and its associated quantities are not as reliable as those for experiments conducted on or after July 22. Nevertheless, the count rate changes per kilogram of $11 \%{ }^{240} \mathrm{Pu}$ shown in Tables $\mathrm{V}$ and VI compare quite favorably with tlie corresponding figures of Tables II, III, and IV.

Table VII compares the field distortion parameter $K$ for five different removal experiments by level. Entries for the December 2 and July 22 experiments are average values; those for the June 19 and 20 experiments are for removals of $6 \mathrm{~kg}$ from each level and have been multiplied by 2.5 to compensate for the shorter run times. All data in Table VII show the effects of removing known amounts of plutonium from each level while all other 


\section{REMOVAL EXPERIMENT OF DECEMBER 2} USING ALL DE.TECTORSa

\begin{tabular}{|c|c|c|c|c|c|c|c|}
\hline \multirow[b]{2}{*}{ Cubiçle Level } & \multirow[b]{2}{*}{ Action } & \multirow{2}{*}{$\begin{array}{l}\text { Total Count } \\
\text { Rate } C_{R}(\mathrm{~Hz}) \\
\end{array}$} & \multirow[b]{2}{*}{$x^{2}$} & \multirow{2}{*}{$\begin{array}{c}\text { Field } \\
\text { Distortion } \mathrm{b} \\
\text { Parameter } \\
\end{array}$} & \multirow{2}{*}{$\begin{array}{l}\text { Change in } \\
\text { Count Rate } \\
\Delta C_{R}(H z) \\
\end{array}$} & \multicolumn{2}{|c|}{ Total Count Rate Change/ kg } \\
\hline & & & & & & $26 \%{ }^{240} \mathrm{Pu}$ & $11 \%{ }^{240} \mathrm{Pu}$ \\
\hline $5 C$ and $6 C^{c}$ & removed & 50391 & --- & -- & --- & --- & $-\cdots$ \\
\hline $3 A$ & inserted & 50983 & 3592 & 6.07 & 592 & 98.7 & 39.5 \\
\hline $3 A$ & reinserted & 51003 & 3620 & $\dot{5} .92$ & 612 & 102.0 & 40.8 \\
\hline $3 D$ & inserted & 50637 & 491 & 2.00 & 246 & 41.0 & 16.4 \\
\hline $3 D$ & reinserted & 50684 & 681 & 2.32 & 293 & 48.8 & 19.5 \\
\hline $3 F$ & inserted & $50 \dot{0187}$ & 536 & 2.73 & 196 & 32.7 & 13.1 \\
\hline $3 F$ & reinserted & 50611 & 557 & 2.53 & 220 & 36.7 & 14.7 \\
\hline $\begin{array}{l}{ }^{a} \text { Counting for } \\
b_{\text {Field distorti }}\end{array}$ & $\begin{array}{l}\text { JO s; each ru } \\
\text { parameter }\end{array}$ & $\begin{array}{l}\text { as a } 1-\sigma \text { uricert } \\
=x^{2} / \Delta C_{R} \text {. }\end{array}$ & inty of : & $\mathrm{Hz}$ & & & $\cdot$ \\
\hline
\end{tabular}


REMOVAL EXPERIMENT OF DECEMBER 2 - EXCLUDING DETECTOR (4-2)a

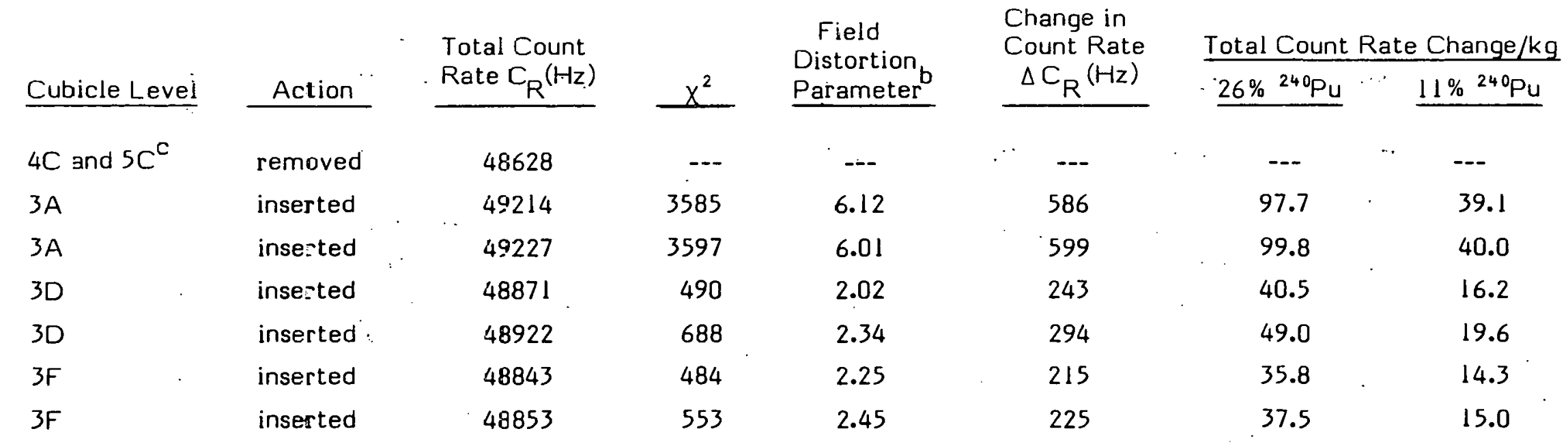

aCounting for $500 \mathrm{~s}$; each run has a $1-\sigma$ uncertainty of $\pm 10 \mathrm{~Hz}$.

bField parameter $K=\chi^{2} / \Delta C_{R}$.

C Two canisters containing $6 \mathrm{~kg}$ of $26 \%{ }^{240} \mathrm{Pu}$ were removed from these cubicles. The removed material was inserted into the other cubicle levels, which were empty. at the time of the experiment. 
REMOVAL EXPERIMENT OF JULY 22 USING ALL DETECTORS ${ }^{a}$

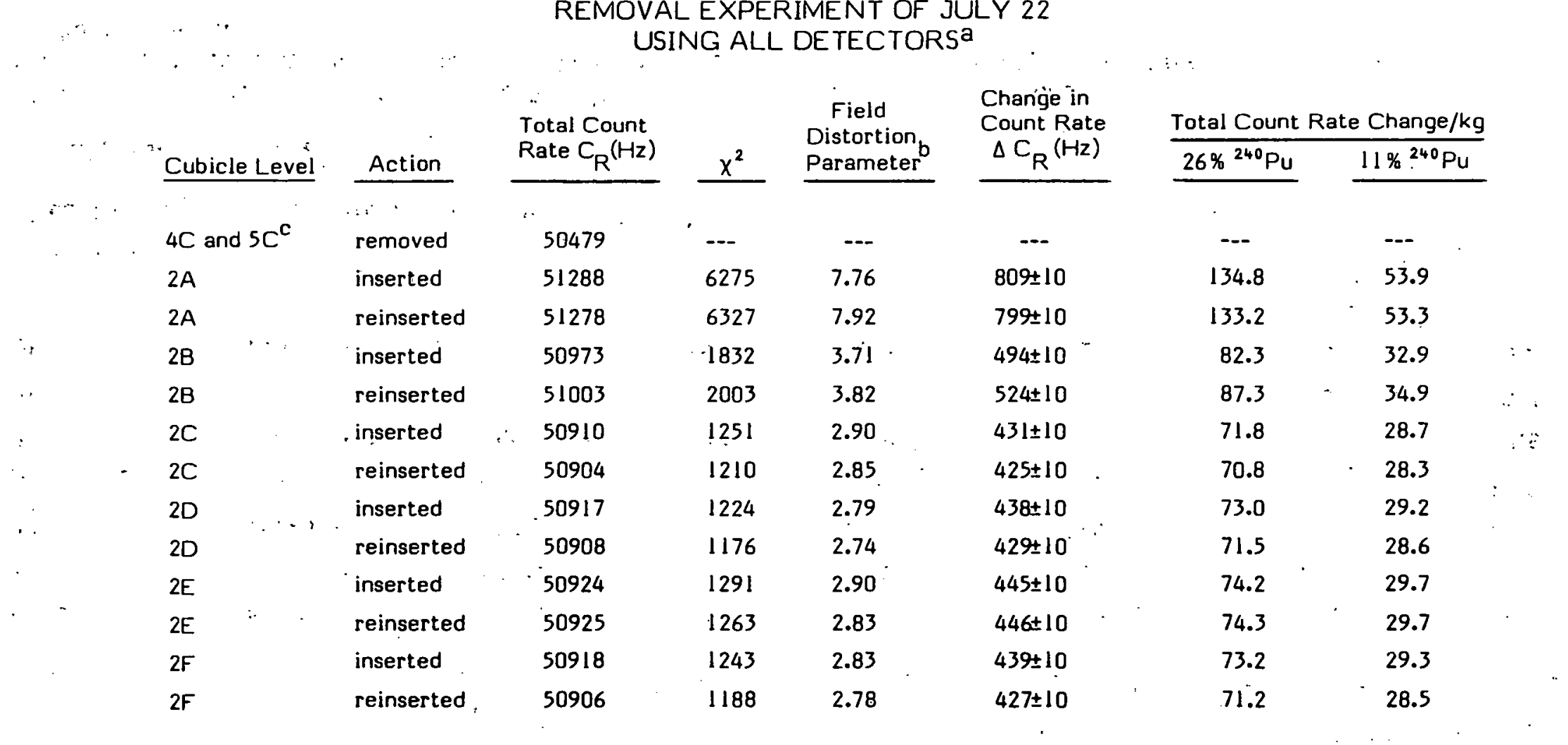

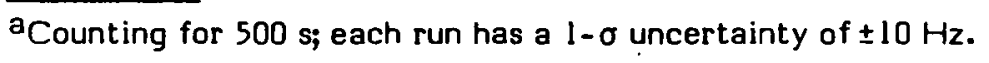

$b_{K}=x^{2} / \Delta C_{R}$.

CTwo canisters containing $6 \mathrm{~kg}$ of $26 \%{ }^{240} \mathrm{Pu}$ were removed from these cubicles. The removed material was inserted into the other cubicle levels, which were empty at the time of the experiment. 
TABLE V

REMOVAL EXPERIMENT OF JUNE 19 USING ALL DETECTORS ${ }^{a}$

\begin{tabular}{|c|c|c|c|c|c|c|}
\hline Cubicle Level & Action & $\begin{array}{l}\text { Total Count } \\
\text { Rate } C_{R}(\mathrm{~Hz})\end{array}$ & $x^{2}$ & $\begin{array}{l}\text { Field } \\
\text { Distortion } \\
\text { Parameter } \\
\end{array}$ & $\begin{array}{l}\text { Change in } \\
\text { Count Rate } \\
\Delta C_{R}{ }^{(H z)} \\
\end{array}$ & $\begin{array}{c}\begin{array}{c}\text { Total Count } \\
\text { Rate Change/ kg } \\
26 \%{ }^{240} \mathrm{Pu} \\
\end{array} \\
\end{array}$ \\
\hline Baseline & $--\cdot$ & 51865 & --- & -- & --- &.-- \\
\hline $4 A^{C}$ & removed & 51633 & 275 & 1.19 & $232^{\circ}$ & 38.7 \\
\hline $4 A$ & replaced & 51719 & 94.9 & 0.65 & 146 & 48.7 \\
\hline $4 A$ & replaced & 51805 & 23.2 & 0.38 & 60 & --- \\
\hline 18 & removed & 51715 & 130 & 0.87 & 150. & 25 \\
\hline 48 & replaced & 51766 & 50.7 & 0.51 & $9 \dot{9}$ & 33 \\
\hline $4 B$ & replaced & 51847 & 23.9 & 1.32 & 18 & --- \\
\hline $4 C$ & removed & 51704 & 121 & 0.75 & 161 & 26.8 \\
\hline $4 C$ & replaced & 51755 & 54.7 & 0.49 & 110 & 36.7 \\
\hline $4 \mathrm{C}$ & replaced & 51811 & 37.3 & 0.69 & 54 & --- \\
\hline $4 D$ & removed & 51745 & 101 & 0.84 & 120 & 20 \\
\hline $4 \mathrm{D}$ & replaced & 51812 & 41.8 & 1.27 & 53 & 17.3 \\
\hline $4 D$ & replaced & 51840 & 26.4 & 1.06 & 25 & $\cdots$ \\
\hline $4 E$ & removed & 51750 & 87.3 & 0.76 & 115 & 19.2 \\
\hline $4 E$ & replaced & 51818 & 28.0 & 0.60 & 47 & 15.7 \\
\hline $4 E$ & replaced & 51858 & 36.0 & 5.14 & 7 & --- \\
\hline $4 \mathrm{~F}$ & removed & 51779 & 68.4 & 0.79 & 85 & 14.2 \\
\hline $4 \mathrm{~F}$ & replaced & 51849 & 24.3 & 1.52 & 16 & 5.3 \\
\hline $4 F$ & replaced & 51922 & 51.1 & 0.90 & 57 & -- \\
\hline
\end{tabular}

\footnotetext{
${ }^{a}$ Counting for $200 \mathrm{~s}$; each run has a $1-\sigma$ uncertainty of $\pm 16 \mathrm{~Hz}$.

${ }^{b}$ Field distortion parameter. $K=x / \Delta C_{R}$.

c Configuration changes correspond to removals starting with the top level in a cubicle and progressing to the bottom level.
}

contributors to the observed count rate are held constant. For the June 20 experiment, we removed plutonium from different locations at the same level. For rernoval experiments performed on or after July 22, Table VII shows decreasing values of $K$ as we removed plutonium from successively lower levels.

The removal experiments in Tables II-VI show that the removal sensitivity for a kilogram of $11 \%{ }^{240} \mathrm{Pu}$ varies from 52 to about $20 \mathrm{~Hz}$ depending on level and cubicle location in the vault. Using data from previously tabulated removal experiments, a partial map of removal sensitivity versus cubicle location can be compiled for the removal of $1 \mathrm{~kg}$ of $11 \%{ }^{240} \mathrm{Pu}$ for a top level in 10 storage cubicles (Fig. 16). From the map, one observes that the removal sensitivity is reasonably constant throughout the vault at an average of 45 counts $/ \mathrm{s} / \mathrm{kg}$; all but one measurement (in cubicle 8 ) fall within about $20 \%$ of this value. ${ }^{8}$ 


\section{TABLE VI}

REMOVAL EXPERIMENT OF JUNE $2 U$ USING ALL UETECTORSa

\begin{tabular}{|c|c|c|c|c|c|c|}
\hline \multirow[b]{2}{*}{ Cubicle Level } & \multirow[b]{2}{*}{ Action } & \multirow{2}{*}{$\begin{array}{l}\text { Total Count } \\
\text { Rate } C_{R^{(H z)}} \\
\end{array}$} & \multirow[b]{2}{*}{$x^{2}$} & \multirow{2}{*}{$\begin{array}{c}\text { Field } \\
\text { Distortion } b \\
\text { Parameter } \\
\end{array}$} & \multirow{2}{*}{$\begin{array}{l}\text { Change in } \\
\text { Count Rate } \\
\Delta C_{R}(H z)\end{array}$} & $\begin{array}{l}\text { Total Count } \\
\text { Rate Change/ kg }\end{array}$ \\
\hline & & & & & & $11 \%^{240} \mathrm{Pu}$ \\
\hline Baseline & --- & 51878 & --- & --- & $-\cdot$ & --- \\
\hline $7 A$ and $I A^{C}$ & removed & 51551 & 381 & 1.17 & 327 & 54.5 \\
\hline $7 A$ & replaced & 51708 & 135 & 0.79 & 170 & 56.7 \\
\hline $1 \mathrm{~A}$ & replaced & 51828 & 31.1 & 0.622 & 50 & --- \\
\hline $7 B$ and $1 B$ & removed & 51640 & 190 & 0.79 & 238 & 39.7 \\
\hline $7 B$ & replaced & 51713 & 100 & 0.61 & 165 & 55.0 \\
\hline 18 & replaced & 51781 & 54.1 & 0.56 & 97 & --- \\
\hline $7 C$ and $1 C$ & removed & 51623 & 197 & 0.77 & 255 & 42.5 \\
\hline $7 C$ & replaced & 51728 & $10 ?$ & 0.71 & 10 & 3.3 \\
\hline $1 \mathrm{C}$ & replaced & 51774 & 59.6 & 0.57 & 104 & -- \\
\hline 70 and 10 & removed & 51733 & 123.8 & 0.85 & 145 & 24.2 \\
\hline 70 & replaced & 51803 & 65.6 & 0.87 & 75 & 25.0 \\
\hline 10 & replaced & 51866 & 35.5 & 2.96 & 12 & --- \\
\hline $7 E$ and $I E$ & removed & 51731 & 111 & 0.76 & 147 & 24.5 \\
\hline $7 E$ & replaced & 51811 & 74.1 & 0.90 & 67 & 22.3 \\
\hline$I E$ & replaced & 51885 & 36.8 & 5.26 & 7 & --- \\
\hline $7 \mathrm{~F}$ and $\mathrm{IF}$ & removed & 51737 & 100 & 0.71 & 141 & 23.5 \\
\hline $7 F$ & replaced & 51800 & 79.1 & 0.99 & 78 & 26.0 \\
\hline $1 F$ & replaced & 51895 & 25.4 & 0.67 & 17 & --- \\
\hline
\end{tabular}

${ }^{a}$ Counting for $200 \mathrm{~s}$; each run has a $1-\sigma$ uncertainty of $\pm 16 \mathrm{~Hz}$.

${ }^{b}$ Field distortion parameter $K=\chi^{2} / \Delta C_{R}$.

c Configuration changes correspond to removals starting with the top level in a cubicle and progressing to the bottom level.

\section{CUNCLUSIONS AND SUMMIARY}

The neutron monitoring experiments conducted in the ZPPR vault successfully demonstrated the feasibility of using ${ }^{3} \mathrm{He}$ proportional counters to measure the neutron field in a plutonium storage vault. During the experiments, count rate stability at the \pm 0.04 to $\pm 0.05 \%$ level was maintained for extended periods of time. A removal sensitivity of about $1 \mathrm{~kg}$ of plutonium from a nominal vault inventory of $2500 \mathrm{~kg}$ was achieved. This sensitivity applies to removal from any storage location in the vault and is based on 4000-s counting periods. Statistically, for this situation, we had predicted a false-alarm rate with a l-kg trip level to result in one false alarm per $2 \mathrm{yr}$ of continuous monitoring. The 8 -month vault monitoring experience at ZPPR indicates that, with only modest hardware improvements, this level can be achieved. 


\section{TABLE VII}

\section{COMPARISON OF FIELD DISTORTION PARAMETERS FOR REMOVAL EXPERIMENTS}

\begin{tabular}{|c|c|c|c|c|c|}
\hline Level & December $2^{\mathrm{a}}$ & November 25 & July $22^{a}$ & June $20^{\mathrm{b}}$ & June $19^{b}$ \\
\hline$A$ & 6.1 & 6.4 & 7.8 & 2.9 & 3.0 \\
\hline $\mathrm{B}$ & --- & 2.6 & 3.8 & 2.0 & $\therefore 2.2$ \\
\hline C & --- & 2.5 & 2.9 & 1.9 & 1.9 \\
\hline$D$ & $2: 2$ & 2.4 & 2.8 & 2.1 & 2.1 \\
\hline$E$ & $\ldots$ & --- & 2.9 & 1.9 & 1.9 \\
\hline$F$ & 2.4 & 2.5 & 2.8 & 1.8 & 2.0 \\
\hline
\end{tabular}

a Average values.

bValues multiplied by 2.5 to compensate for shorter run times.



Fig. 16.

Partial map of removal sensitivities for the top levels of selected cubicles. The sensitivites correspond to the removal of $1 \mathrm{~kg}$ of $11 \%{ }^{240} \mathrm{Pu}$. 
Our findings indicate that the field distortion parameter $K$ for the top levels differs significantly from $K$ for all other levels. This is to be expected for spatially peaked distributions because the corresponding $x^{2}$ values weight the individual detector excursions as the square of the excursion, which leads to a much larger $x^{2}$ for a given change in total count rate if that change occurs primarily in a few detectors instead of in many.

The practical import of the foregoing observation is that a change in system count rate can be attributed to a removal from a given storage level in the cubicle, using the observed field distortion parameter. With this information, one may then accurately interpret a given change in count rate in terms of a missing plutonium mass.

For example, a change in count rate of 40 counts/s corresponds to a removal of $2 \mathrm{~kg}$ of plutonium if $\mathrm{K}$ is about 3, but corresponds to a removal of $1 \mathrm{~kg}$ of plutonium if $\mathrm{K}>6$. The ability to interpret count rate changes in terms of the field distortion parameter makes it possible to use neutron monitoring for vault inventory purposes. Based on our measurements, we predict that the vault monitoring system can provide surveillance of a $2500-\mathrm{kg}$ plutonium inventory in real time at a sensitivity level of $\pm 1 \mathrm{~kg}$ of plutonium.

\section{ACKNOWLEDGMENTS}

We wish to acknowledge the many individuals at Argonne National Laboratory West who provided both administrative and technical assistance that enabled the successful completion of this project. In particular, we express our thanks for the outstanding level of support provided by the ZPPR staff.

\section{REFERENCES}

1. J. T. Caldwell, P. E. Fehlau, S. W. France, and A. A. Robba, "New Approaches to Rapid Nondestructive Verification of Plutonium Fuels," in "Eoncepts for Inventory Verification in Critical Facilities," D. D. Cobb, Ed., Los Alamos Scientific Laboratory report LA-7315 (1978), pp. Al3-Al6.

2. J. T. Caldwell, P. E. Fehlau, S. W. France, and A. A. Robba, "Rapid NDA Scanning System for FCA Plutonium Fuel Verification," in "Nuclear Safeguards Research and Development Program Status Report, January-April 1978," G. R. Keepin and W. H. Chambers, Eds., Los Alamos Scientific Laboratory report LA-7439-PR (1978), pp. 68-69.

3. S. D. Gardner, Ed., "Fuel Drawer Scanner," in "Nuclear Safeguards Research and Development Program Status Report, April-June 1979," Los Alamos Scientific Laboratory report LA-7991-PR (1979), p. 21.

4. J. T. Caldwell, P. E. Fehlau, and A. A. Robba, "Fast Critical Assembly Plutonium Storage Vault Monitor," in "Nuclear Safeguards Research and Development Program Status Report, January-April 1978," Los Alamos Scientific Laboratory report LA-7439 (1978), pp. 66-67. 
5. J. T. Caldwell, J. C. Pratt, R. D. Hastings, S. W. France, E. R. Shunk, and T. H. Kuckertz, "ZPPR Vault Monitor," in "Nuclear Safeguards Research and Development Program Status Report, October-December 1979," G. R. Keepin, Ed., Los Alamos Scientific Laboratory report LA-8241-PR (1980), pp. 15-16.

6. J. C. Pratt, J. T. Caldwell, S. W. France, R. D. Hastings, H. H. Hsu, and E. R. Shunk, "Rapid Fuel Drawer Scanner for Fast Critical Assembly Safeguards," 2lst Annual Meeting of the Institute of Nuclear Materials Management, Pälm Beach, Florida, June 30-July 2, 1.980; Nuclear Materials Management IX, 795-809 (1980).

7. J. C. Pratt, J. T. Caldwell, R. D. Hastings, S. W. France, E. R. Shunk, J. M. Bieri, and T. H. Kuckertz, "ZPPR Vault Monitor," in "Nuclear Safeguards Research and Development Program Status Report, January-March 1980," G. R. Keepin, Ed., Los Alamos Scientific Laboratory report LA-8373-PR (1980), pp. 26-28.

8. J. T. Caldwell, R. D. Hastings, E. R. Shunk, J. C. Pratt, T. H. Kuckertz, and R. Goin, "Fast Critical Assembly Plutonium Vault Monitoring System," in "Nuclear Safeguards Research and Development Program Status Report, July-September 1980," G. R. Keepin, Ed., Los Alamos National Laboratory report LA-8590-PR (1981), p. 25. 


\section{GLOSSARY}

CPM control program/microprocessor

DOE . Department of Energy

IC integrated circuit

INEL Idaho National Engineering Laboratory

TTL transistor-to-transistor logic

ZPPR Zero.Power Plutonium Reactor 


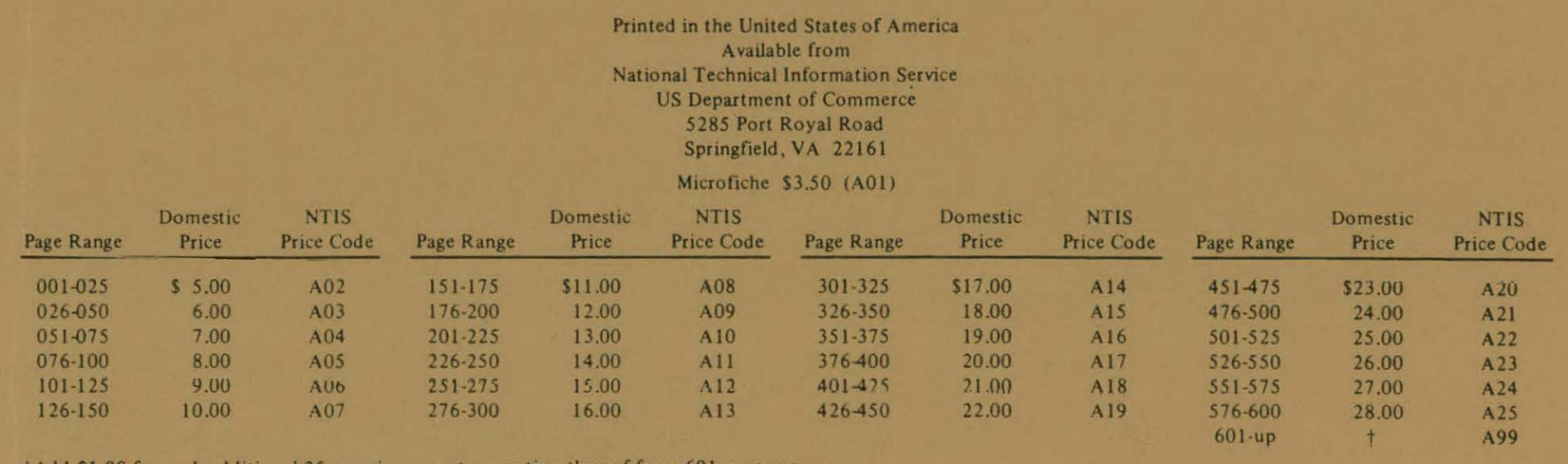

†Add $\$ 1.00$ for each additional 25-page increment or portion thereof from 601 pages up. 
